\title{
Meta-analysis of the incidence of foodborne pathogens in Portuguese meats and their products
}

\author{
C. Xavier, U. Gonzales-Barron *, V. Paula, L. Estevinho, V. Cadavez \\ CIMO Mountain Research Centre, School of Agriculture (ESA), Polytechnic Institute of Braganza, Portugal
}

\section{A R T I C L E I N F O}

\section{Article history:}

Received 6 August 2013

Accepted 15 November 2013

\section{Keywords:}

Salmonella

Listeria monocytogenes

Beef

Pork

Broiler

Sausages

\begin{abstract}
A B S T R A C T
Meat and meat products are the main vehicles of foodborne diseases in humans caused by pathogens such as Salmonella spp., Campylobacter spp., Listeria monocytogenes, Yersinia enterocolitica, verotoxigenic Escherichia coli (VTEC) and Staphylococcus aureus. In order to prioritise research on those microbial hazards, a meta-analysis study was conducted to summarise available information on the presence of such pathogens in meats produced in Portugal. By using a logit-transformed proportion as effect size parameterisation, a number of multilevel random-effect meta-analysis models were fitted to estimate mean occurrence rates of pathogens, and to compare them among meat categories (i.e., bovine meat, broiler meat, pork, minced beef and minced pork), and among meat product categories (i.e., intended to be eaten cooked, to be eaten raw and cured meats). The mean occurrence rate of Campylobacter in Portuguese broiler meat (40\%; 95\% CI: 22.0-61.4\%) was about ten times higher than that of Salmonella (4.0\%; 95\% CI: 1.4-10.8\%); although these levels were comparable to current EU ranges. Nevertheless, in the other meat categories, the meta-analysed incidences of Salmonella were slightly to moderately higher than EU averages. A semi-quantitative risk ranking of pathogens in Portuguese-produced pork pointed Salmonella spp. as critical (with a mean occurrence of 12.6\%; 95\% CI: 8.0-19.3\%), and Y. enterocolitica as high (6.8\%; 95\% CI: 2.2-19.3\%). In the case of the Portuguese meat products, the non-compliance to EU microbiological criteria for L. monocytogenes (8.8\%; 95\% CI: 6.5-11.8\%) and Salmonella spp. (9.7\%; 95\% CI: 7.0-13.4\%) at sample units level, in the categories 'intended to be eaten cooked' and 'to be eaten raw', were considerably higher than EU levels for ready-to-eat products in comparable categories. S. aureus was the pathogen of greatest concern given its high occurrence (22.6\%; 95\% CI: 15.4-31.8\%) in meat products. These results emphasised the necessity of Portuguese food safety agencies to take monitoring, and training actions for the maintenance of good hygiene practices during the production of the great variety of traditional meat products. This meta-analysis study also highlighted important gaps of knowledge, and may assist food safety authorities in the prioritisation of microbiological hazards, and the implementation of essential food safety assurance systems at primary production.
\end{abstract}

(c) 2013 Elsevier Ltd. All rights reserved.

\section{Introduction}

Raw meat provides an ideal growth medium for a wide range of pathogens, and, if there is any malpractice in the handling, postprocessing, storage or cooking of the product, illness can be a real possibility. Contamination of meat with foodborne pathogens is a major public health issue. In fact, in 2011, campylobacteriosis was the most commonly reported gastrointestinal bacterial pathogen in humans in the EU, followed by salmonellosis, with 220,209 and 95,548 confirmed cases, respectively While campylobacteriosis has increased significantly over the past four reported years (2008-2011), salmonellosis continues its decreasing trend since 2007 although it is the most reported cause of outbreaks (EFSA, 2013). In particular, the human cases caused by the two most common serovars, Salmonella Enteritidis (44\%) and Salmonella Typhimurium (25\%), diminished significantly since 2008. In foodstuffs, the highest proportion of Campylobacter positive samples was once

\footnotetext{
* Corresponding author. Tel.: + 351273303325.

E-mail address: ubarron@ipb.pt (U. Gonzales-Barron).
}

again reported for fresh poultry (31.3\% of positive samples), while Salmonella serovars were most often detected in fresh broiler (6.7\%) and pig meat $(0.7 \%)$. Furthermore, non-compliance with the EU Salmonella criteria has been most often observed in foods of meat origin, being higher for minced poultry (6.8\% based on sample units) and minced meat from other species $(1.1 \%)$ intended to be eaten cooked and minced meat and meat preparations intended to be eaten raw (1.6\%) (EFSA, 2013).

In the case of the verotoxigenic Escherichia coli (VTEC) infections (9485 cases), a 2.6-fold increase was observed in comparison to 2010, while the confirmed EU cases of human listeriosis (1476) was slightly lower than previous years, yet with a high fatality rate of $12 \%$ (EFSA, 2013). Contaminated bovine meat (1.4\% of contaminated sample units in 2011) continues to be considered the major source of VTEC infections in humans (EFSA, 2012, 2013), while non-compliance with the EU Listeria monocytogenes criteria is mostly observed in ready-to-eat (RTE) fishery products (6.7\%) and of meat origin (2.4\%). In 2011, although following a decreasing five-year trend, yersiniosis was the fourth most frequently reported zoonosis (7017 confirmed cases) in 
the EU. Pigs are considered to be a major reservoir while pork and poultry products are considered to be the most important source of pathogenic Yersinia enterocolitica infection in humans (Simonová, Vazlerová \& Steinhauserová, 2007). In fact, in pig meat samples taken from four European countries, the overall incidence of $Y$. enterocolitica was $2.4 \%$ (EFSA, 2013).

In Portugal, there is considerably less information on zoonoses, and incidence of pathogens in meats. Because of the current compulsory national surveillance, and control programmes of Salmonella in foods, more information is available for this pathogen. According to the last EFSA report (EFSA, 2013), the notification rates of salmonellosis in 2011 ( 1.6 confirmed cases per 100,000) appeared lower than the EU average $(20.7$ per 100,000$)$, and, peculiarly, well below other Western European countries such as Spain (32.8 per 100,000), France (13.4 per $100,000)$ and Denmark (21.0 per 100,000). However, as Portugal has one of the highest hospitalisation rates ( $84 \%$ as pointed out in the same report), this may indicate that, apart from a likely large number of citizens not seeking medical advice, there is also under-reporting by the surveillance systems which capture primarily the most severe cases. With regard to the foodstuff contaminated with Salmonella spp. in Portugal, pig meat has been identified as the most important likely source of infection, with a mean incidence of $5.0 \%$, in comparison with the EU average of $0.6 \%$ (EFSA, 2013). Nevertheless, information with regard to other foodborne diseases is scarce (i.e., no Portuguese surveillance systems in place for campylobacteriosis, listeriosis, yersiniosis and VTEC infections), which leads to an inaccurate evaluation of the relative importance of each foodborne disease. Due to the limited zoonosis information, it is difficult to establish an evolution trend of the incidence of foodborne diseases as well as the occurrence of the main microbial contaminants in Portuguese foods in the last years (Veiga et al., 2012). Nonetheless, given (i) the strong association of foodborne diseases in humans with the consumption of contaminated meat and meat products, and (ii) the high consumption of meats (93 kg per Portuguese habitant in 2012 above the average $80 \mathrm{~kg}$ per EU citizen) and meat products (672 tonnes production in 2009 in Portugal), it is imperative to gather as much information as possible on the levels of foodborne pathogens in Portuguese meats and meat products in order to understand the current epidemiological situation, prioritise microbial hazards for risk analysis, and identify knowledge gaps to provide direction for further research.

Meta-analysis is a body of summarising statistical techniques whose objective is to synthesise, integrate and contrast the results from a large amount of primary studies investigating the same research question (Gonzales-Barron, Cadavez, Sheridan, \& Butler, 2013). The primary objective of meta-analysis is to produce a more precise estimate of the effect size of a particular treatment, with increased statistical power, than is possible using only a single study (Sutton, Abrams, \& Jones, 2001). Yet, with meta-analysis, it is also possible to explain differences in the study outcomes by coding study characteristics, such as: research design features, data collection procedures, type of samples or even year (Hox \& De Leeuw, 2003). In the past few years, meta-analysis has increasingly been applied in food safety (Den Besten \& Zwietering, 2012; Gonzales Barron, Bergin, \& Butler, 2008; Gonzales-Barron \& Butler, 2011; Gonzales-Barron et al., 2013; Grieg et al., 2012; McQuestin, Shadbolt, \& Ross, 2009; Sánchez, Dohoo, Christensen, \& Rajic, 2007). In food safety research, meta-analysis may be conducted to address a broad range of research questions such as disease incidence, prevalence of microorganisms in foods, effect of interventions pre- and postharvest, risk ranking of pathogens and consumer practices, among others. Thus, the objectives of this research are: (i) to compile all publicly accessible information on the occurrence of Salmonella spp., Campylobacter, L. monocytogenes, VTEC, Y. enterocolitica and Staphylococcus aureus in Portuguese meats, and meat products grouped by categories; (ii) to quantitatively summarise, and compare the occurrence of pathogens according to available information by conducting separate meta-analysis models for meat and meat products; (iii) to appraise likely publication bias, a common artefact in meta-analysis studies (Viechtbauer, 2010); (iv) to conduct a semi-quantitative risk ranking of pathogens in pork using the characterisation of severity of hazards proposed in EFSA (2011a); and (iv) to identify knowledge gaps on the occurrence of pathogens in certain meat categories.

\section{Methodology}

The problem statement in this study was the estimation of the overall incidence or occurrence of foodborne pathogens in Portuguese meats. The population was specified as meat and meat products produced in Portugal while the measured outcome is the detection of pathogens in meats sampled either at processing plants or at retail. Following the systematic review protocol presented by Sargeant, Amezcua, Rajic, and Waddell (2005), electronic searches were carried out to identify official reports published by national and international organisations (such as World Health Organisation, WHO; European Food Safety Authority, EFSA; International Commission for Microbiological Specification in Foods, ICMSF) reporting occurrence values of Salmonella spp., Campylobacter, L. monocytogenes, VTEC, Y. enterocolitica and S. aureus in Portuguese meats (categorised as: fresh bovine, fresh broiler, fresh pork, minced beef and minced pork) and meat products (categorised as: intended to be eaten raw, intended to be eaten cooked, and cured meats). Literature search to identify suitable scientific articles was conducted using the ISI Web of Knowledge and Web of Science databases for papers indexed since 1990 as well as Google searches using both English and Portuguese terms for combinations of foodborne disease or zoonosis (e.g., salmonellosis) or the pathogen (e.g., Salmonella), and the meat under study (e.g., pig meat, pork, pork product, pork preparation, sausage). For inclusion in the meta-analyses, the papers had to meet two requirements: to be an original article, and to make use of an approved microbiological method for pathogen detection.

Following the formulation of the problem statement and data collection, a parameterisation or measure unit of the effect size needs to be determined. The parameter measuring the effect size is a common metric that permits direct comparison and summation of primary studies (Noble, 2006). The effect size ( $\theta$ ) refers to the degree to which the hypothetical phenomenon (i.e., pathogens in meats) is present in the population. Because the measured outcome is binary (i.e., a meat sample tests either positive or negative for the pathogen) and is given only for single groups, the only possible parameter to measure effect size is the raw proportion $p$ (or incidence) and its transformations. In order to restrict the range of the effect size or pathogen's incidence to [0-1] and to stabilise the variance, the logit transformation of the raw proportion was used as the effect size measure $\theta$ (Viechtbauer, 2010). If the sample size $n$ of the primary study is at least higher than 20 , it is usually reasonable to assume that the sampling distribution of the outcomes is normal (Bryk \& Raudenbush, 1992).

\subsection{Description of data sets}

After assessing all the information presented in every study, a total of 21 primary studies - encompassing international reports and scientific articles - were considered appropriate for inclusion in the metaanalysis models. The meta-analysis models for fresh meats were based on 16 primary studies (Antunes, Reu, Sousa, Pestana, \& Peixe, 2002; Baptista, 2010; Borges, 2009; EFSA, 2005, 2006, 2007, 2009, 2010a 2010b, 2011b, 2012, 2013; Esteves, Aymerich, et al., 2006; Esteves, Saraiva, Fontes, \& Martins, 2006; Mena et al., 2004; Mena, Rodrigues, Silva, Gibbs, \& Teixeira, 2008), while the ones for meat products were based on 7 primary studies (Almeida, Mena, \& Carneiro, 1998; Esteves, Aymerich, et al., 2006; Esteves, Patarata, Saraiva, \& Martins, 2008; Esteves, Saraiva, et al., 2006; Ferreira, Fraqueza, \& Barreto, 2007; Mena et al., 2004; Mendes, 2013; Vaz-Velho, Almeida, Mena, Carneiro, \& Freitas, 1998). From each of the primary studies ( $j$ ), the number of samples $(s)$ experiencing the event of interest (i.e., testing positive for a 
Table 1

Number of incidence and observations $(s / n)$ of food-borne pathogens in Portuguese fresh meats by category extracted from published survey studies.

\begin{tabular}{|c|c|c|c|c|c|}
\hline Pathogen & Fresh bovine & Fresh broiler & Fresh pork & Minced beef & Minced pork \\
\hline Salmonella & $\begin{array}{l}3 \\
(11 / 180),(0 / 55),(0 / 1142)\end{array}$ & $\begin{array}{l}7 \\
(1 / 81),(4 / 216),(0 / 25) \\
(2 / 50),(0 / 40),(44 / 421) \\
(7 / 64)\end{array}$ & $\begin{array}{l}12 \\
(3 / 60),(25 / 105),(6 / 58),(2 / 61),(5 / 30) \\
(62 / 1122),(39 / 256),(14 / 99) .(16 / 99) \\
(25 / 105),(13 / 101),(10 / 64)\end{array}$ & $\begin{array}{l}2 \\
(0 / 95),(3 / 135)\end{array}$ & $\begin{array}{l}5 \\
(13 / 130),(2 / 73),(5 / 186) \\
(2 / 142),(3 / 120)\end{array}$ \\
\hline Campylobacter & 0 & $\begin{array}{l}8 \\
(17 / 81),(21 / 108),(0 / 33), \\
(296 / 421),(21 / 78),(39 / 78), \\
(46 / 62),(24 / 38)\end{array}$ & 0 & 0 & 0 \\
\hline Y. enterocolitica & 0 & 0 & $\begin{array}{l}3 \\
(0 / 61),(0 / 58),(1 / 61)\end{array}$ & 0 & $\begin{array}{l}4 \\
(13 / 25),(10 / 25),(2 / 75),(0 / 74)\end{array}$ \\
\hline VTEC & 0 & 0 & $\begin{array}{l}3 \\
(0 / 74),(0 / 34),(4 / 25)\end{array}$ & 0 & $\begin{array}{l}1 \\
(5 / 50)\end{array}$ \\
\hline L. monocytogenes & $\begin{array}{l}1 \\
(3 / 17)\end{array}$ & $\begin{array}{l}2 \\
(26 / 63),(9 / 15)\end{array}$ & 0 & 0 & 0 \\
\hline S. aureus & 0 & $\begin{array}{l}1 \\
(28 / 64)\end{array}$ & $\begin{array}{l}1 \\
(32 / 64)\end{array}$ & 0 & 0 \\
\hline
\end{tabular}

pathogen) and the total number of samples $(n)$ were extracted. Information such as sample weight, production stage, sampling site of the carcass (if applicable) and year of the survey was also annotated from every primary study. For the Portuguese fresh meats, a total of fiftyone observations of incidence $(s / n)$ of foodborne pathogens were extracted from the 16 primary studies, and are compiled according to meat categories in Table 1.

In the case of the Portuguese meat products, sixty-nine incidence observations on pathogens were found for 26 types of products. These were mainly traditional meat products elaborated with pig meat and fat, and were categorised as traditional products 'to be eaten raw' (encompassing different kinds of dry-fermented sausages) and 'to be eaten cooked' (including fresh sausages and blood sausages). A third category of 'cured meat products' was considered so as to comprise heat-treated meat products such as cooked sliced ham and mortadella. These three meat product categories are mutually exclusive, and the observations of incidence of pathogens per category are summarised in Table 2. Y. enterocolitica, VTEC and Campylobacter have not been listed in Table 2 due to the absence of incidence data of such pathogens in meat products.

\subsection{Random-effects meta-analysis}

In its simplest form, a meta-analysis can be carried out as a fixedeffects variant to make a conditional inference only about the $J$ primary studies included (Hedges \& Vevea, 1998). However, most metaanalyses are based on sets of studies that are not exactly identical in their methods and the characteristics of their samples, which may introduce variability (i.e., heterogeneity) among the true effects estimated by the primary studies. One way to model the heterogeneity is to treat it as purely random (Viechtbauer, 2010). In contrast to the fixed effects model, random models provide an unconditional inference about a larger set of studies from which the $J$ studies included in the meta-analysis are assumed to be a random sample (Hedges \& Vevea, 1998). It envisions a hypothetical population of studies that comprises studies that have been conducted, that could have been conducted or that may be conducted in the future. The random-effects model addresses the question: How large is the average true effect in this larger population of studies? In a random effects model, each primary study investigates its own true effect size $\Theta_{j}$,

$\theta_{j}=\Theta_{j}+\varepsilon_{j}=\bar{\Theta}+v_{j}+\varepsilon_{j}$

where $\theta_{j}$ is the observed effect size in the primary study $j, \bar{\Theta}_{j}$ the mean true effect size, and $\varepsilon_{j}$ the error due to sampling variance. The $\varepsilon_{j}$ are assumed to be normally-distributed with mean zero and true variance $\xi^{2}$. The term $v_{j}$ represents the deviation of the true study effect size $\Theta_{j}$ from the mean true effect size. The values of $v_{j}$ are normally-distributed random effects with mean zero and variance $\tau^{2}$. Thus, it follows that for a random-effects meta-analysis model, $\theta_{j} \sim \operatorname{Normal}\left(\Theta, \tau^{2}+\xi^{2}\right)$. In this approach, two sources of variation are distinguished: sampling variation $\left(\xi^{2}\right)$, and variation between true effect sizes $\left(\tau^{2}\right)$. By including this additional component $\left(\tau^{2}\right)$, the standard error in the effect size estimates represents random variability at both the subject level and the study level. Notice that the nomenclature $\theta_{j}$ and $\Theta_{j}$ is a general notation that refers to any effect size measure for the observed and the true effect size, respectively. In our particular case, it refers to the logit transformation of the incidence or proportion $p_{j}$, which is calculated using the number of successes $s_{j}$ (positive samples) and total sample size $n_{j}$ taken from each of the primary studies.

$\theta_{j}=\operatorname{logit} p_{j}=\log \left(\frac{p_{j}}{1-p_{j}}\right)=\log \left(\frac{s_{j}}{n_{j}-s_{j}}\right)$.

The incidence or proportion $p_{j}$ can be back-transformed as,

$$
p_{j}=\frac{\exp \left(\theta_{j}\right)}{1+\exp \left(\theta_{j}\right)} .
$$

Table 2

Number of incidence and observations $(s / n)$ of food-borne pathogens in Portuguese meat products by category extracted from published survey studies.

\begin{tabular}{|c|c|c|c|}
\hline Pathogen & Intended to be eaten raw & Intended to be eaten cooked & Cured meats \\
\hline $\begin{array}{l}\text { L. } \\
\text { monocytogenes }\end{array}$ & $\begin{array}{l}14 \\
(1 / 12),(4 / 16),(1 / 15),(1 / 8),(1 / 8),(1 / 7),(1 / 8),(0 / 6),(0 / 10),(2 / 38), \\
(1 / 30),(1 / 44),(1 / 27),(0 / 48)\end{array}$ & $\begin{array}{l}11 \\
(3 / 26),(3 / 24),(1 / 11),(0 / 10),(1 / 11),(0 / 10),(1 / 10),(1 / 10),(0 / 32), \\
(10 / 96),(1 / 9)\end{array}$ & $\begin{array}{l}3 \\
(0 / 66),(0 / 42),(1 / 4)\end{array}$ \\
\hline Salmonella & $\begin{array}{l}10 \\
(1 / 23),(1 / 7),(1 / 15),(0 / 6),(0 / 10),(1 / 38),(1 / 30),(0 / 6),(0 / 6),(0 / 3)\end{array}$ & $\begin{array}{l}13 \\
(0 / 19),(3 / 9),(1 / 1),(1 / 15),(1 / 2),(3 / 10),(0 / 11),(0 / 10),(0 / 10) \\
(1 / 10),(2 / 32),(12 / 96),(0 / 10)\end{array}$ & $\begin{array}{l}2 \\
(1 / 107),(0 / 51)\end{array}$ \\
\hline S. aureus & $\begin{array}{l}6 \\
(1 / 10),(8 / 38),(4 / 30),(2 / 6),(0 / 6),(1 / 3)\end{array}$ & $\begin{array}{l}7 \\
(1 / 10),(3 / 11),(0 / 10),(2 / 10),(0 / 10),(6 / 32),(48 / 96)\end{array}$ & 0 \\
\hline
\end{tabular}


Apart from the values of $\theta_{j}$ from each primary study, the standard error of the effect size must be calculated. The variance of the sampling distribution of the transformed variable is known from statistical theory as

$\sigma^{2}\left(\theta_{j}\right)=\frac{1}{n_{j} p_{j}\left(1-p_{j}\right)}$

In order to estimate the mean true effect size from Eq. (1), the observed effect sizes $\theta_{j}$ should be averaged. However, since primary studies usually differ from each other in the reliability of estimating the true effect size (for instance, due to differences in study sizes), a weighted average is preferred with weights $w^{*}{ }_{j}$ equal to the precision in estimating the population effect size.

$w_{j}^{*}=\frac{1}{\sigma^{2}\left(\theta_{j}\right)+\tau^{2}}$

The variance $\tau^{2}$ is estimated from the Q-statistic (DerSimonian \& Laird, 1986),

$\hat{\tau}^{2}=\frac{Q-(J-1)}{\sum_{j} w_{j}-\left(\sum_{j} w_{j}^{2} / \sum_{j} w_{j}^{j}\right)}$

where $w_{j}$ are the weights that would be assigned in a simple fixedeffects model, and $Q$ is a popular statistic used to test the presence of heterogeneity in effect size across primary studies (Cochran, 1954).

$w_{j}=\frac{1}{\sigma^{2}\left(\theta_{j}\right)}$

$Q=\sum_{j} \frac{\left(\theta_{j}-\hat{\Theta}\right)^{2}}{\sigma^{2}\left(\theta_{j}\right)}$.

When effect sizes across studies are homogeneous, $Q$ follows a chisquare distribution with $(j-1) \mathrm{df}$. If the hypothesis is rejected, there is evidence that there are additional sources of variability $\left(\tau^{2}\right)$ other than within-study sampling error $\left(\xi^{2}\right)$. It is then common practice either to examine moderating variables; to divide the studies in homogeneous groups to perform separate meta-analysis; or to use a random-effects or a multilevel model.

The mean true effect size $\Theta$ and its standard error $\sigma(\Theta)$ are now estimated from Eqs. (9) and (10) using instead the corrected weights $w^{*}{ }_{j}$.

$\hat{\Theta}=\frac{\sum_{j} w_{j}^{*} \theta_{j}}{\sum_{j} w_{j}^{*}}$

$\hat{\sigma}(\hat{\Theta})=\frac{1}{\left(\sum_{j} w_{j}^{*}\right)^{0.5}}$

To evaluate whether the effect size is larger than zero, often a Wald test assuming normality for the dependent variable is used comparing the estimated weighted average divided by its standard error with a standard normal distribution $(U=\hat{\Theta} / \hat{\sigma}(\hat{\Theta}))$. The $U$ statistic is compared with a chi-square distribution with one df.

\subsection{Multilevel meta-analysis}

A meta-analysis can be considered a special case of multilevel analysis using hierarchical linear models, with subjects between studies at the first level and studies at the second level. In a multilevel metaanalysis, as in any other multilevel analyses, one usually starts from the random-effects model (Van den Noortgate \& Onghena, 2003). If the between-study variance is shown to be noteworthy, study characteristics or moderators can be added to the model to account for at least part of the heterogeneity in the true effects. This leads to the mixed-effects model given by:

$\theta_{j}=\Theta_{j}+\varepsilon_{j}=\beta_{0}+\sum_{s=1}^{S} \beta_{s} X_{s j}+v_{j}+\varepsilon_{j}$

with $S\left(X_{1}\right.$ to $\left.X_{S}\right)$ study characteristics. This model treats the moderator effects $\beta_{s}$ as fixed, and $v_{j}$ as random effects that distribute normally with a mean zero and a variance of $\tau^{2}$. Yet, $\tau^{2}$ now denotes the amount of residual heterogeneity among the true effects, or the variability among the true effects that is not accounted for by the $S$ moderators included in the model. The goal of the analysis is then to examine to what extent the moderators influence the size of the average true effect size $\Theta$. The resulting model is thus more general than the ones commonly used in classical meta-analysis. If no predictors are included, the model of Eq. (11) simplifies to the random-effects model (Eq. (1)), or if the variance in true effects is zero, to the fixed-effects model. The use of a regression equation $\left(\beta_{0}+\sum_{s=1}^{S} \beta_{s} X_{s j}\right)$ for the study characteristics is appealing for several reasons. First, different predictors can easily be investigated together; meaning that even possible inter-correlations can be taken into account, which is not the case when separate metaanalyses are performed to investigate the moderating effects of study characteristics. Secondly, regression is a general approach that can be used for continuous as well as for categorical moderator variables (Van den Noortgate \& Onghena, 2003).

\subsection{Fitting of models}

To estimate the parameters, maximum likelihood estimation (MLE) procedures are most frequently used. In MLE, residuals on both levels $\left(v_{j}\right.$ and $\varepsilon_{j}$ of Eq. (1)) are assumed to be independently distributed. To test the fixed parameters of the model $\left(\beta_{s}\right)$, the Wald test is used like in the traditional approaches, comparing the parameter estimate by the standard error with a standard normal distribution. Apart from the Q statistic, other measures can be computed to facilitate the interpretation of the estimated amount of between-study heterogeneity $\left(\tau^{2}\right)$. The $\mathrm{I}^{2}$ statistics or intra-class correlation estimates the proportion of between-study variance from the total variance. This is analogous to using the proportion of explained variance in standard regression models to indicate the importance of specific predictor variables. Hunter and Schmidt (1990) pointed out that, when the number of studies is small, a lack of significance for $\tau^{2}$ does not imply that the outcomes are homogeneous. So, they proposed a $25 \%$ rule of thumb; this is, if the intra-class variance $\mathrm{I}^{2}$ is higher than $25 \%$ of the total variance, the variance between studies can be deemed as large enough to attempt to model it using available study characteristics. The $\mathrm{I}^{2}$ statistic is just a monotonic transformation of $\tau^{2}$ (see Higgins \& Thompson, 2002).

For models including moderators, an omnibus or moderators test (QM test) of all model coefficients is conducted that excludes the intercept. By default, the test statistics of the individual coefficients in the model are based on the normal distribution, while the moderators test is based on a chi-square distribution with $S$ degrees of freedom $(S$ being the number of moderators tested). Finally, after attempting to explain the heterogeneity among studies using the study characteristics, 
the QE test can be performed to test the non-explained (residual) variance using the statistic (Raudenbush \& Bryk, 1985)

$Q E=\sum_{j} \frac{\left(\theta_{j}-\hat{\beta}_{0}-\sum_{s=1}^{S} \hat{\beta}_{s} w_{s j}\right)^{2}}{\sigma^{2}\left(\theta_{j}\right)}$

which follows a chi-square distribution with $J-S-1^{\circ}$ of freedom.

As there was considerable dispersion in the number of incidence observations among the meat category - pathogen combinations (Tables 1 and 2), separate meta-analysis studies were conducted on suitable data groups of the combinations presenting more observations. For the meat categories, these were: (i) a meta-analysis on the incidence of Salmonella spp. across meat categories; (ii) a meta-analysis on the incidence of Salmonella spp., Campylobacter and L. monocytogenes in fresh broiler; and (iii) a meta-analysis on the incidence of Salmonella spp., Y. enterocolitica, VTEC and S. aureus in pork (fresh and minced) for a semi-quantitative risk ranking. For each of the three meta-analyses of pathogens in meats, a random-effects meta-analysis was fitted. The objective of this meta-analysis was to estimate the mean effect size (mean incidence) as well as to assess between-study heterogeneity. Subsequently, multilevel meta-analysis models (Gonzales-Barron et al., 2013) were fitted to each of the three studies using categorical variables, defined as 'meat category' for study (i), and 'pathogen' for studies (ii) and (iii). The general statistical notation of the multilevel model (Eq. (11)) became either $\theta_{j}=\beta_{0}+\left(\beta_{1} X_{1 j}+\beta_{2} X_{2 j} \ldots+\beta_{p} X_{p j}\right)+v_{j}+$ $\varepsilon_{j}$ or $\theta_{j}=\beta_{0}+\left(\beta_{1} X_{1 j}+\beta_{2} X_{2 j} \ldots+\beta_{m} X_{m j}\right)+v_{j}+\varepsilon_{j}$, where the vector $\left(\beta_{1}, \beta_{2}, \ldots, \beta_{p}\right)$ or $\left(\beta_{1}, \beta_{2}, \ldots, \beta_{m}\right)$ refers to the shift in effect size coefficients of each pathogen or each meat category for the multilevel model either with pathogens or with meat categories as subgroups, respectively. The coded variable $X_{p}$ or $X_{m}$ takes the value of 1 for the pathogen or meat category subgroup. The objective of fitting meta-analyses with a moderator was to assess any statistical difference between subgroups $\left(\mathrm{H}_{0}: \beta_{1}=\beta_{2}\right.$ $\left.\ldots=\beta_{p / m}=0\right)$. Notice that, in this work, the subscript $j$ used in the above equations is general and indistinctly refers to the incidence entry unit for each of the meta-analysis (random-effects and multilevel).

In the case of the meat products, three separate meta-analysis studies were performed on the incidence of each of the three pathogens, L. monocytogenes, Salmonella spp., and S. aureus. For each of the three studies, a random-effects meta-analysis was first adjusted; and subsequently, a multilevel meta-analysis model using 'meat product' as a categorical moderating variable of three levels $\left(\theta_{j}=\beta_{0}+\left(\beta_{1} X_{1 j}+\beta_{2}\right.\right.$ $\left.\left.X_{2 j}+\beta_{3} X_{3 j}\right)+v_{j}+\varepsilon_{j}\right)$. Meta-analysis models were adjusted in $\mathrm{R}$ version 2.14.2 (R Development Core Team) using the 'metafor' package (Viechtbauer, 2010), which provides functions for fitting the various models described above as well as meta-analytical graphs (forest plots, funnel plots, etc.).

\subsection{Semi-quantitative risk ranking of pathogens in Portuguese raw pork}

With the available information of occurrence rates of some pathogens in Portuguese raw pork, a preliminary semi-quantitative risk ranking of Salmonella spp., Y. enterocolitica, VTEC and S. aureus was conducted to identify the top pathogens in terms of public health importance as related to raw pork and potential foodborne infections. The FAO risk assessment grid (FAO, 1998) that qualitatively ranks risk in terms of two variables: severity and likelihood of occurrence, was employed in this study. The categorisation used for the severity of disease was the one developed by EFSA (2011a), where the severity of human infection was assessed using lethality among confirmed cases as an indicator, without taking into account whether pork was identified as a source of infection of a case. Using this definition, the severity of consequences is "high" when the human cases are higher than 10/ 100,000 and case-fatalities are lower than $0.1 \%$. The severity of consequences is "medium" when the human cases are between in 1 and 10/
100,000 , and case-fatalities are lower than $0.1 \%$. Lastly, the severity of consequences in pork is low in two cases: when the human cases are lower than $1 / 100,000$ and case-fatalities higher than $0.1 \%$, or when the human cases are lower than 1/100,000 and case-fatalities lower than 0.1\% (EFSA, 2011a). According to this severity categorisation, Salmonella spp. belongs to high severity, Y. enterocolitica to medium severity, while VTEC belongs to low severity. EFSA (2011a) gives S. aureus a qualitative category of unknown because of the lack of data on frequency and case fatality of confirmed cases.

The second variable is the likelihood of occurrence of the pathogen, which ideally should be measured at the point of consumption. However, in practice this type of data is not available, and instead prevalence data at a slaughterhouse or at retail level was used. Occurrence - or even better, concentration - data for the pathogen either at retail level or at another point further up the chain would give some measure of the likelihood of occurrence of the pathogen for the purposes of the risk ranking grid. Thus, in our research, the likelihood of occurrence of a pathogen was replaced by a quantitative estimation of its incidence, obtained by summarising all the occurrences from the primary studies. Box plots of the incidence rates were approached by fitting a beta distribution $\left(s_{T}+1, n_{T}-s_{T}+1\right)$ to the incidence data of each of the pathogens (Vose, 2008), where $s_{T}$ is the total of pooled number of successes (total number of positive samples from all primary studies) and $n_{T}$ the total sample size.

\section{Results and discussion}

Although there is a perception that a high incidence of foodborne diseases may have various causes such as inadequate manipulation, preparation and distribution of foods along the food chain, it is also true that quantitative risk assessment leading to efficient prevention demands data availability. Overall, in Portugal, data on microbial contaminants in meats and epidemiology is relatively scarce. For instance, at the level of national compulsory surveillance of infectious diseases, salmonellosis and brucellosis are the only food-related illnesses caused by bacteria subject to notification. In relation to zoonotic agent outbreaks, in 2011, Portugal reported 8 confirmed outbreaks due to toxins of S. aureus and Clostridium spp. which affected a total of 101 people (EFSA, 2013). Nevertheless, it is not possible to obtain any information about the types of food that mostly contributed to the notified individual cases and outbreaks. The most recent register of the associated foods dates back from 2000, and is found in a report of the European monitoring programme for foodborne disease control (WHO, 2003). According to this study, the foodstuffs mostly associated to the outbreaks in Portugal, in the period 1999-2000, belonged to meat and meat products (21\%), followed by baked products (14\%) and ready-to-eat meals (22\%). Despite the 12-year difference, EFSA (2013) reinforced that meat and meat products - although at EU level - were still the main vehicle of foodborne diseases, responsible for $32 \%$ of the strong evidence outbreaks in 2011. In this way, whether eating habits in Portugal have remained basically unchanged in the past decade or the Portuguese situation is well approached by the EU trend, it is imperative to gather as much information as possible on the foodborne pathogens present in Portuguese meats in order to understand the current epidemiological situation, and to allocate resources to prioritise microbial hazards for risk analysis.

The systematic review conducted in this study indicated that currently the information on the level of occurrence of certain pathogens in meats produced in Portugal is sparse. The foodborne pathogens whose presence in meats have not been extensively surveyed are Campylobacter (with only 8 published studies identified), Y. enterocolitica (7 primary studies), VTEC and L. monocytogenes (3 primary studies) and S. aureus ( 2 primary studies). For these pathogens, there is no knowledge (Table 1) on their occurrence or levels in fresh bovine meat, except for one study found for L. monocytogenes, and generally no knowledge of their levels in any minced type of meat (i.e., minced beef, minced poultry, 
Reference

Incidence $[95 \% \mathrm{Cl}]$

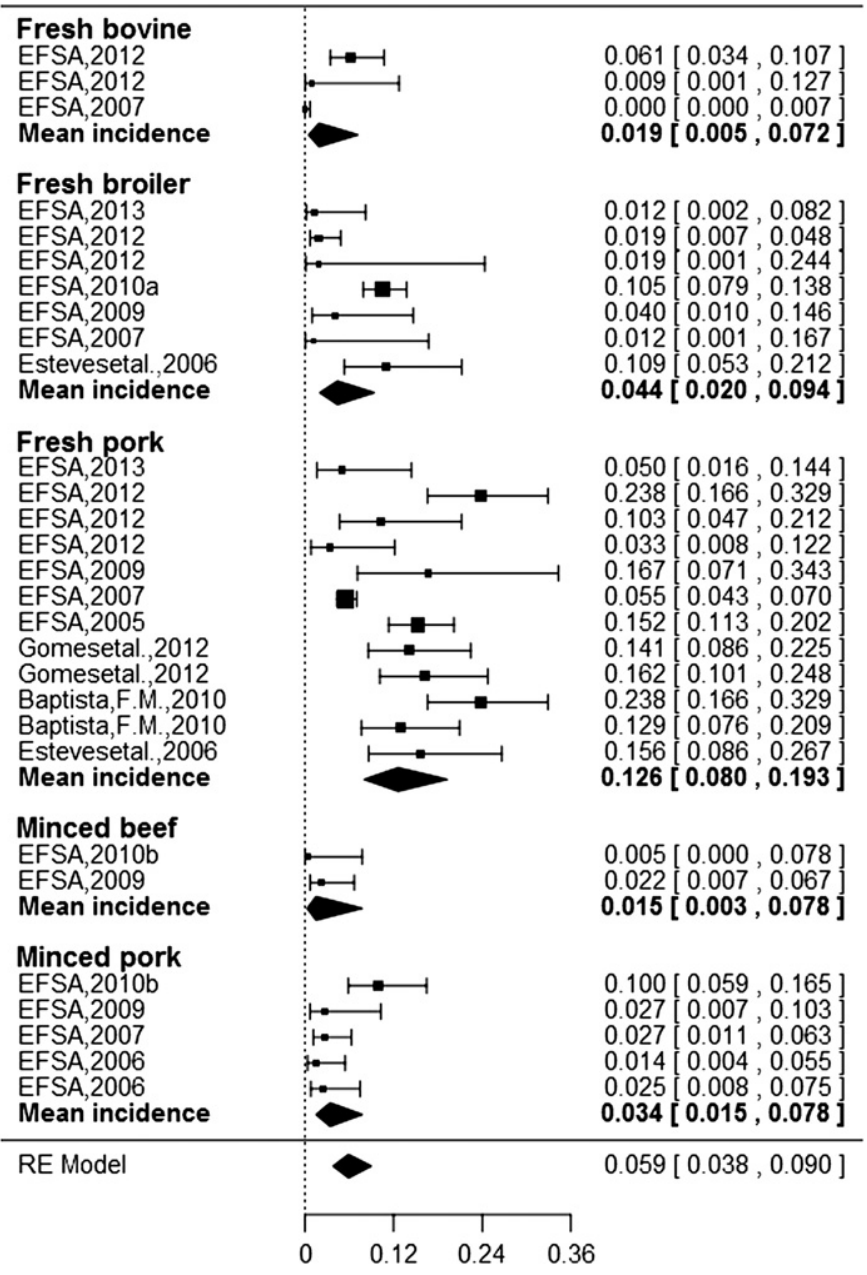

Fig. 1. Forest plot of the multilevel random-effects models of incidence of Salmonella spp. in Portuguese meats.

minced pork). Likewise, no single study reporting incidence or numbers of $Y$. enterocolitica in broiler meat or Campylobacter in pork have been found. Except for minced broiler meat, Salmonella spp. comes out as the only pathogen that has been widely examined in most of the meat categories with 29 primary studies retrieved. This data availability has been prompted by the current national programmes in place to control Salmonella in bovine, pig and broiler meat sampled at processing plants and retail. Moreover, the EU mandatory Salmonella monitoring programmes at primary production, as well as the enforced food safety criteria for Salmonella (Reg. No. 1441/2007) setting limits for specific food categories, have in turn prompted more scientific research of this pathogen with an integrated food-chain approach.

\subsection{Incidence of pathogens in Portuguese meats}

The first random-effects meta-analysis indicated that the incidence of Salmonella spp. in Portuguese meats is 6\% (CI: 4-9\%). As displayed in the forest plot (Fig. 1), considerable variability in reported incidence were observed among studies, which was proven by the significant test of heterogeneity $(\mathrm{Q}=171 ; \mathrm{p}<0.001$ in Table 3$)$. The between-study variance decreased from $\tau^{2}=1.21$ to 0.58 when meats were grouped in categories by the multilevel model, although there was still some unexplained residual heterogeneity $(\mathrm{QE}=130 ; \mathrm{p}<0.001$ in Table 3$)$. The omnibus moderator test $(\mathrm{QM})$ showed that the mean incidence of at least one meat category differed significantly from the others (Table 3). Despite fresh pork corresponds to the category presenting the higher between-study variability (Fig. 1), it is undoubtedly the one with the highest incidence of Salmonella spp., diverging significantly from fresh bovine and fresh broiler meat. In contrast with the EU average occurrence for Salmonella in fresh pork (0.7\%; EFSA, 2013) and minced pork (0.6\%; EFSA, 2012), the corresponding occurrence values for Portugal, $12.6 \%$ (95\% CI: 8.0-19\%) and 3.4\% (95\% CI 1.5-7.8\%) are much higher. This finding may be due to the fact that in Portugal there is no bacteriological or serological control programme of pigs on farm that could enable the application of risk management strategies at primary production. Because Salmonella is primarily located in the gastrointestinal tract of sub-clinically infected pigs, they introduce the pathogen to the slaughterhouse through their internal organs, skin, faeces, and the cross-contamination of carcasses is basically a matter of redistributing Salmonella bacteria from positive pigs during the various slaughter processes. In a risk assessment model, Gonzales Barron et al. (2009) underscored the need to target Salmonella contamination at swine production, calculating that on average $77 \%$ of the variability in the total contaminated carcasses at the point of evisceration is explained by the contamination from the carrier animals entering the slaughter lines. Thus, although in Portugal there is a national monitoring programme for Salmonella in pig meat based on sampling at slaughterhouse and meat cutting plants, the incidence of Salmonella in pork is still high, as its control requires rather a systematic approach from farm to fork with specific risk management strategies in place also at farm level. This fact, along with the high consumption of pork in Portugal (43 kg/habitant/year), calls for the contemplation of the implementation of a national Salmonella monitoring programme of pig herds. Referring to serovars, the most common ones present in Portuguese fresh pork include Typhimurium (37, 70\%), Derby (11, 14\%) and Rissen (7, 14\%) (as recovered by Baptista, 2010; Gomes-Neves et al., 2012), which belong to the most frequent serovars in pigs and pig meat isolated in the EU (EFSA, 2013).

In relation to the fresh bovine meat and minced beef produced in Portugal, the meta-analysed occurrences of Salmonella are 1.9\% (95\% CI: $0.5-7.2 \%$ ) and $1.5 \%$ (95\% CI: 0.3-7.8\%), respectively (Fig. 1), which

Table 3

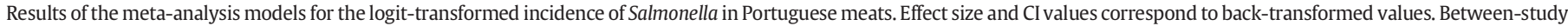

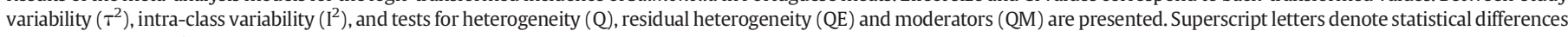
among meat categories.

\begin{tabular}{|c|c|c|c|c|c|}
\hline Meta-analysis type & Effect size Incidence $(\mathrm{CI})$ & $\tau^{2}$ & $\mathrm{I}^{2}(\%)$ & $\mathrm{QM}(\mathrm{F})$ & $\mathrm{Q} / \mathrm{QE}$ \\
\hline Overall random-effects & $0.059(0.038-0.090)^{* * *}$ & 1.21 & $91.6^{*}$ & - & $\begin{array}{l}171^{* * *} \\
(\mathrm{df}=28)\end{array}$ \\
\hline \multicolumn{6}{|l|}{ Multilevel } \\
\hline Fresh bovine & $0.019(0.005-0.072)^{\mathrm{a}}$ & $0.58^{* *}$ & - & $49.7^{* * *}$ & $130^{* * *}$ \\
\hline Fresh poultry & $0.044(0.020-0.094)^{\mathrm{ab}}$ & & & $(\mathrm{df} 1=5, \mathrm{df} 2=24)$ & $(\mathrm{df}=24)$ \\
\hline Fresh pork & $0.126(0.080-0.193)^{\mathrm{c}}$ & & & & \\
\hline Minced beef & $0.015(0.003-0.078)^{\mathrm{a}}$ & & & & \\
\hline Minced pork & $0.034(0.015-0.078)^{\mathrm{ab}}$ & & & & \\
\hline
\end{tabular}

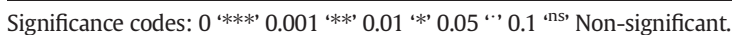




\begin{tabular}{|c|c|c|}
\hline \multicolumn{3}{|l|}{ Salmonella } \\
\hline EFSA, 2013 & $\mapsto$ & $0.012[0.002,0.082]$ \\
\hline EFSA, 2012 & p-1 & $0.019[0.007,0.048]$ \\
\hline EFSA, 2012 & 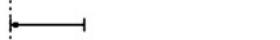 & $0.019[0.001,0.244]$ \\
\hline EFSA, 2010a & $=$ & $0.105[0.079,0.138]$ \\
\hline EFSA, 2009 & $\sum_{0 \rightarrow 1}$ & $0.040[0.010,0.146]$ \\
\hline EFSA, 2007 & 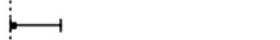 & $0.012[0.001,0.167]$ \\
\hline Esteves et al., 2006 & $\mapsto-1$ & $0.109[0.053,0.212]$ \\
\hline Mean incidence & - & $0.040[0.014,0.108]$ \\
\hline \multicolumn{3}{|l|}{ Campylobacter } \\
\hline EFSA, 2013 & $\mapsto-1$ & $0.210[0.135,0.312]$ \\
\hline EFSA, 2012 & $\mapsto-1$ & $0.194[0.130,0.280]$ \\
\hline EFSA, 2010a & 분 & $0.703[0.658,0.745]$ \\
\hline EFSA, 2005 & $\longrightarrow$ & $0.015[0.001,0.196]$ \\
\hline Borges, 2009 & $\mapsto-1$ & $0.269[0.183,0.378]$ \\
\hline Borges, 2009 & $\longmapsto$ & $0.500[0.391,0.609]$ \\
\hline Mena et al., 2008 & $\longmapsto-1$ & $0.742[0.620,0.836]$ \\
\hline Mena et al., 2008 & $\longmapsto$ & $0.632[0.470,0.768]$ \\
\hline Mean incidence & & $0.403[0.220,0.618]$ \\
\hline \multicolumn{3}{|l|}{ L. monocytogenes } \\
\hline Mena et al., 2004 & & $0.600[0.348,0.808]$ \\
\hline Antunes et al., 2002 & $\longmapsto$ & $0.413[0.299,0.537]$ \\
\hline Mean incidence & & $0.499[0.148,0.851]$ \\
\hline \multirow[t]{3}{*}{ RE Model } & & $0.181[0.082,0.353]$ \\
\hline & 1 & 7 \\
\hline & $\begin{array}{llll}0.2 & 0.4 & 0.6 & 0.8\end{array}$ & 1 \\
\hline
\end{tabular}

Fig. 2. Forest plot of the multilevel random-effects models of incidence of Salmonella spp., Campylobacter and L. monocytogenes in fresh broiler produced in Portugal.

are values moderately higher than the current EU average $(0.2 \%$ and $0.4 \%$, respectively; EFSA, 2013). On the contrary, the mean Salmonella occurrence in fresh broiler produced in Portugal (4.4\%; 95 CI: 2.0 9.4\%) appeared to be within the EU level (5.9\%). A knowledge gap was found with regard to the Salmonella serovars most frequently recovered from Portuguese bovine and broiler meats.

Our study also summarised the occurrence of some pathogens in fresh broiler meat produced in Portugal. The discrepancy among the incidence values of the different pathogens can be visualised in the multilevel meta-analysis forest plot (Fig. 2). As expected, this led to a high between-study heterogeneity $\left(\tau^{2}=3.22\right.$; $\mathrm{Q}=453$ with $\mathrm{p}<0.001$ in Table 4) which still remained significant after categorising the effect sizes by pathogen $\left(\tau^{2}=1.16 ; \mathrm{QE}=178\right.$ with $\left.\mathrm{p}<0.001\right)$. Although a higher between-study variability was observed for Campylobacter in comparison with both Salmonella and L. monocytogenes incidence values (Fig. 2), still the omnibus moderator test (QM) showed that the mean incidence of at least one pathogen differed significantly from the others (Table 4). The fact that Salmonella spp. in broiler meat had at least ten times lower incidence than Campylobacter and L. monocytogenes (Table 4 ) is believed to be due to the positive impact of the national
Salmonella control programmes at the primary production; this is, in flocks of laying hens, breeding flocks and broiler flocks, with risk reduction targets set in 2007. It is also deemed that the EU compulsory food safety criteria for Salmonella (Reg. No. 1441/2007) setting limits for products of meat origin may have contributed to the overall reduction of this pathogen in poultry. The same cannot be said for Campylobacter in fresh broiler as its high incidence in Portugal (40.3\%; CI: 22.061.8\%) follows the high EU average trend (31.3\%; EFSA, 2013). Since 2005, campylobacteriosis continues to be the most commonly reported foodborne disease in the EU, with broiler meat considered to be the major source of the disease. EFSA (2013) concluded that handling, preparation and consumption of broiler meat may account for $20-30 \%$ of human campylobacteriosis in the EU, whilst $50-80 \%$ may be attributed to the chicken reservoir as a whole. Moreover, $46 \%$ of the Campylobacter outbreaks in the EU in 2011, in which the implicated food vehicle was provided, were associated to broiler meat (EFSA, 2013). Nevertheless, it is unfeasible to explore such a link in Portugal since campylobacteriosis cases are neither notified nor its food vehicle investigated. Some research has shown that Campylobacter jejuni $(15,70 \%)$ and Campylobacter coli $(40,70 \%)$ are the two species of highest incidence in Portuguese fresh broiler (as extracted from Borges, 2009; Mena et al., 2008). While there continues to be a lack of epidemiological and risk assessment studies of Campylobacter in Portuguese broiler meat, control measures can only be directed to the consumers. Through food labelling and education campaigns, Portuguese consumers should be made aware that adequate cooking will assure safety of meats but serious undercooking or cross contamination from a raw to a cooked product in the kitchen are thought to be major routes of infection.

The association of $L$. monocytogenes as a pathogen of high prevalence in poultry meat, would be considered by many as surprising. However, due to the fact that the high level of mean occurrence of 50\% (CI: 14.8$85.1 \%$; Fig. 2) has been obtained from only two available primary studies (Antunes et al., 2002; Mena et al., 2004), at present the main recommendation can be for enabling actions to address the data gap. Djeniyi, Wegener, Jensen, and Bisgaard (1996) indicated that because L. monocytogenes is not frequently isolated from chickens, it is likely that the live animals may only contribute little to the total contamination of the abattoir, and that the pathogen may be introduced from dirty transport crates. Even though, poultry has not been associated to a great extent with human listeriosis, variable incidence rates of this pathogen have been found in the past in Denmark (23\%; Djeniyi et al., 1996), USA (30\%; Cox, Bailey, \& Berrang, 1997), Ireland (6-30\%; Whyte, McGill, Monahan, \& Collins, 2004), Northern Ireland (17\%; Soultos, Koidis, \& Madden, 2003) and Brazil (28\%; Loura, Almeida, \& Almeida, 2005). Thus, these and the Portuguese results highlight that the presence of $L$. monocytogenes in Portuguese broiler meat would not be uncommon; and hence, maintaining good hygiene practices in production, processing and the consumer's kitchen cannot be overemphasized.

Within the pork category, occurrence data were available for Salmonella spp., Y. enterocolitica, S. aureus and VTEC (Table 1). The multilevel metaanalysis conducted in this data group also showed that there was significant between-study heterogeneity $(\mathrm{Q}=250 ; \mathrm{p}<0.001$ in Table 5).

Table 4

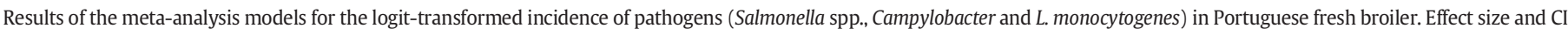

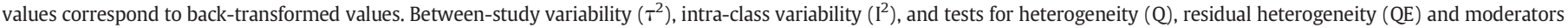
$(\mathrm{QM})$ are presented. Superscript letters denote statistical differences among incidence of pathogens.

\begin{tabular}{|c|c|c|c|c|c|}
\hline Meta-analysis type & Effect size Incidence $(\mathrm{CI})$ & $\tau^{2}$ & $\mathrm{I}^{2}(\%)$ & $\mathrm{QM}(\mathrm{F})$ & $\mathrm{Q} / \mathrm{QE}$ \\
\hline Overall random-effects & $0.181(0.082-0.353)^{* * *}$ & $3.22^{* *}$ & $97.6^{*}$ & - & $\begin{array}{l}453^{* * *} \\
(\mathrm{df}=16)\end{array}$ \\
\hline \multicolumn{6}{|l|}{ Multilevel } \\
\hline Salmonella & $0.040(0.014-0.108)^{\mathrm{a}}$ & 1.16 & - & $13.8^{* * *}$ & $178^{* * *}$ \\
\hline Campylobacter & $0.403(0.220-0.614)^{\mathrm{bc}}$ & & & $(\mathrm{df} 1=3, \mathrm{df} 2=14)$ & $(\mathrm{df}=14)$ \\
\hline L. monocytogenes & $0.499(0.148-0.851)^{c}$ & & & & \\
\hline
\end{tabular}

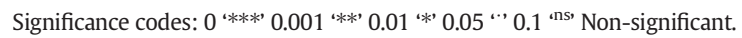


Table 5

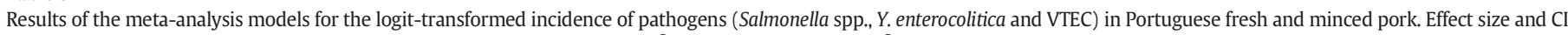

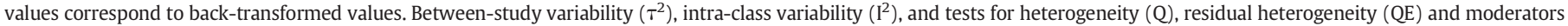
$(\mathrm{QM})$ are presented. Superscript letters denote statistical differences among incidence of pathogens.

\begin{tabular}{|c|c|c|c|c|c|}
\hline Meta-analysis type & Effect size Incidence $(\mathrm{CI})$ & $\tau^{2}$ & $\mathrm{I}^{2}(\%)$ & $\mathrm{QM}(\mathrm{F})$ & $\mathrm{Q} / \mathrm{QE}$ \\
\hline Overall random-effects & $0.085(0.053-0.134)^{\text {*** }}$ & $1.54^{* *}$ & 92.6 & - & $\begin{array}{l}250^{* * *} \\
(\mathrm{df}=28)\end{array}$ \\
\hline \multicolumn{6}{|l|}{ Multilevel } \\
\hline Salmonella & $0.086(0.048-0.152)^{\mathrm{a}}$ & 1.45 & - & $1.5^{*}$ & $173^{* * *}$ \\
\hline Y. enterocolitica & $0.068(0.022-0.193)^{\mathrm{a}}$ & & & $(\mathrm{df} 1=3, \mathrm{df} 2=25)$ & $(\mathrm{df}=25)$ \\
\hline VTEC & $0.056(0.012-0.221)^{a}$ & & & & \\
\hline S. aureus & $0.500(0.073-0.927)^{\mathrm{b}}$ & & & & \\
\hline
\end{tabular}

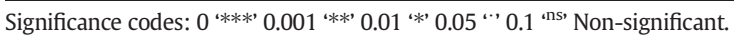

Furthermore, while the mean incidence rates of both Y. enterocolitica and VTEC in pork were numerically lower than the Salmonella mean incidence, yet statistical differences among these occurrence rates could not be revealed (Table 5). Pig meat and pork products are considered to be the most important source of pathogenic $Y$. enterocolitica infections in humans (EFSA, 2012, 2013; Simonová, Vázlerová, \& Steinhauserová, 2007). The meta-analysed mean value of this pathogen in Portuguese pork (6.8\%; 95\% CI: 2.2-19.3\%) was moderately higher than the overall incidence rate of $2.4 \%$ ( 30 out of 1146 samples) reported for four EU countries in 2011 (EFSA, 2013). It is the ability of this organism to grow at $4{ }^{\circ} \mathrm{C}$ which makes refrigerated pork preparations with a relatively long shelf-life a probable source of infection (EFSA, 2005). Although the occurrence of VTEC in Portuguese pork was meta-analysed from only four primary studies, like $Y$. enterocolitica, VTEC's mean occurrence (5.6\%; 95\% CI: $1.2-22.2 \%$ in Table 5) turned out to be higher than the EU average reported over the years 2007-2010 (EFSA, 2012). Many of the investigations reported to EFSA in those years did not yield any positive findings, except for six countries which found VTEC incidence in fresh pig meat at very low levels (0.1$2 \%$ ). VTEC 0157:H7 was detected in three of these national surveys, and the highest proportion of positive samples was reported by Spain (1.2\%; EFSA, 2012). On the other hand, although bovine meat is believed to be a major source of foodborne VTEC infections for humans, no microbiological survey of VTEC in bovine meat has been identified in Portugal. This is an issue that merits attention as VTEC infections in humans have been following an increasing trend since 2006 in a number of European countries such as the Netherlands, Austria, Denmark, Finland, France and Luxembourg (EFSA, 2012).

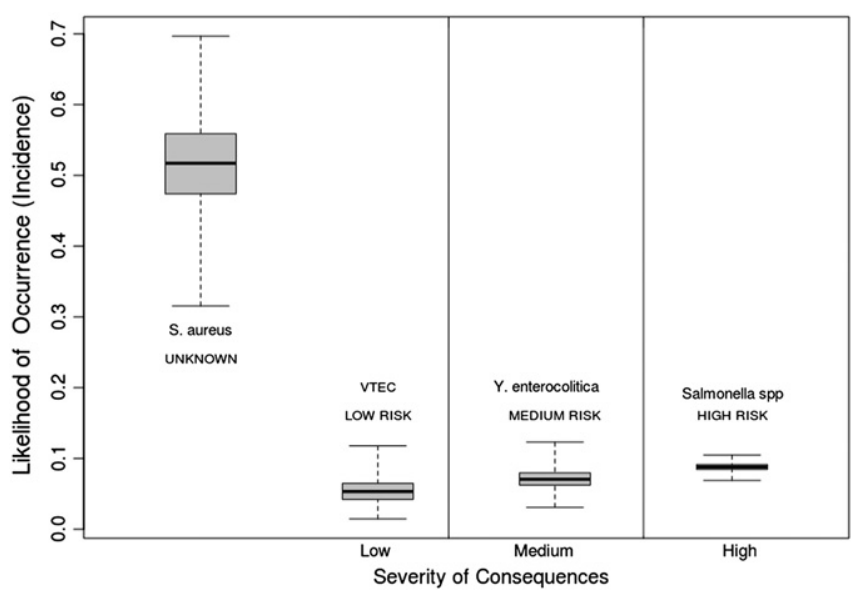

Fig. 3. Semi-quantitative risk ranking of pathogens associated with Portuguese fresh pork. The categorisation of severity of consequences was taken from EFSA (2011a).

\subsection{Risk ranking of pathogens in Portuguese raw pork}

A representation of the semi-quantitative risk ranking is shown in Fig. 3, where the confidence intervals of the box plots do not depict the uncertainty around the mean incidence (which is described by the confidence intervals of the meta-analysed mean incidences of Table 5), but instead the total uncertainty around the true incidence in a Bayesian framework. For this reason, the confidence intervals of the box plots (Fig. 3) are larger than those obtained by meta-analysis in Table 5. The pathogens were then categorised regarding their incidence or frequency of occurrence as per the criterion suggested in EFSA (2011a). This criterion establishes that the frequency of detection can be high, medium or low if the prevalence is higher than $5 \%$, between 0.1 and $5 \%$ and lower than $0.1 \%$, respectively. In our case, all four pathogens were assigned to the "high" frequency of detection category as at least $50 \%$ quartile of their box plot were above the cut-off criterion of $5 \%$.

Bringing together the two variables, severity of disease and likelihood of occurrence, using the risk assessment grid from FAO (1998), it was found that the significance of Salmonella spp. in the fresh pork produced in Portugal is critical while the significance of $Y$. enterocolitica and VTEC is major and minor, respectively. In the case of S. aureus, there was a lack of data on intoxication severity, and also scarce knowledge on the likelihood of occurrence in Portugal (as only one primary study was retrieved). While such study (Esteves, Saraiva, et al., 2006) reported a high mean incidence of $50 \%$ in pork cuts, there is no knowledge on isolated strains capable of toxin formation. It is known that pork-derived products may remain a potential source of meticillin-resistant $S$. aureus (MRSA), with CC398 being the MRSA lineage most commonly associated to intensively-reared food-producing animals. However, so far there is no evidence for increased risk of human colonisation or infection following contact or consumption of food contaminated by CC398 (Smith et al., 2011). Furthermore, as the main risk factors of S. aureus include cross contamination and growth at processing, retail and domestic levels, EFSA (2011a) ranked the significance of $S$. aureus in chilled pig carcasses as low or minor risk. In our preliminary assessment, the microbiological hazards ranking in descending order were then: Salmonella spp., Y. enterocolitica, VTEC, while S. aureus was assigned to an unknown risk category (Fig. 3). A totally different outcome was found when using the ICMSF (2002) criteria for the severity characterisation of pathogens. In such a case, all three pathogens VTEC, Salmonella and Y. enterocolitica represented major risks. Thus, it is imperative that national resources and efforts be allocated to the implementation of a system for control and prevention to reduce, in the first place, the current high levels of Salmonella and Y. enterocolitica in the Portuguese pig herds and at processing level.

\subsection{Incidence of pathogens in Portuguese meat products}

L. monocytogenes has not only been detected in a variety of raw meats, but also in food contaminated post-processing such as cheeses and RTE meats, both of which have been implicated internationally in 
Table 6

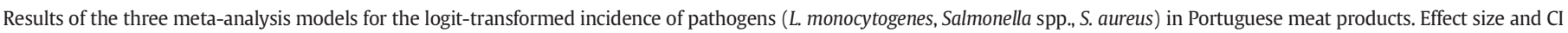

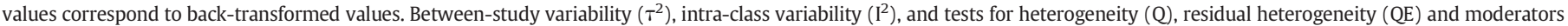
$(\mathrm{QM})$ are presented. Superscript letters denote statistical differences among meat product categories.

\begin{tabular}{|c|c|c|c|c|c|}
\hline Meta-analysis type & Effect size Incidence $(\mathrm{CI})$ & $\tau^{2}$ & $\mathrm{I}^{2}(\%)$ & $\mathrm{QM}(\mathrm{F})$ & $\mathrm{Q} / \mathrm{QE}$ \\
\hline \multicolumn{6}{|l|}{ L. monocytogenes } \\
\hline Fixed-effects & $0.088(0.065-0.118)^{* * *}$ & 0 & 0 & - & $\begin{array}{l}22.2^{\mathrm{ns}} \\
(\mathrm{df}=27)\end{array}$ \\
\hline \multicolumn{6}{|l|}{ Multilevel } \\
\hline To be cooked & $0.098(0.066-0.144)^{\mathrm{a}}$ & - & - & $0.87^{\mathrm{ns}}$ & $20.8^{\mathrm{ns}}$ \\
\hline To be eaten raw & $0.083(0.051-0.131)^{\mathrm{a}}$ & & & $(\mathrm{df} 1=2, \mathrm{df} 2=25)$ & $(\mathrm{df}=25)$ \\
\hline Cured & $0.042(0.010-0.162)^{a}$ & & & & \\
\hline \multicolumn{6}{|l|}{ Salmonella spp. } \\
\hline Fixed-effects & $0.097(0.070-0.134)^{* * *}$ & 0 & 0 & - & $\begin{array}{l}32.5^{\mathrm{ns}} \\
(\mathrm{df}=24)\end{array}$ \\
\hline \multicolumn{6}{|l|}{ Multilevel } \\
\hline To be cooked & $0.134(0.092-0.190)^{\mathrm{c}}$ & - & - & $8.13^{* * *}$ & $18.7^{\mathrm{ns}}$ \\
\hline To be eaten raw & $0.057(0.028-0.113)^{\mathrm{b}}$ & & & $(\mathrm{df} 1=2, \mathrm{df} 2=22)$ & $(\mathrm{df}=22)$ \\
\hline Cured & $0.009(0.002-0.045)^{\mathrm{a}}$ & & & & \\
\hline \multicolumn{6}{|l|}{ S. aureus } \\
\hline Random-effects & $0.226(0.154-0.318)^{* * *}$ & 0.23 & $39.5^{* *}$ & - & $\begin{array}{l}33.5^{* * *} \\
(\mathrm{df}=12)\end{array}$ \\
\hline \multicolumn{6}{|l|}{ Multilevel } \\
\hline To be cooked & $0.258(0.157-0.393)^{\mathrm{b}}$ & 0.24 & - & $13.5^{* * *}$ & $24.0^{*}$ \\
\hline To be eaten raw & $0.184(0.097-0.319)^{\mathrm{a}}$ & & & $(\mathrm{df} 1=2, \mathrm{df} 2=11)$ & $(\mathrm{df}=11)$ \\
\hline
\end{tabular}

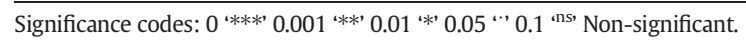

outbreaks. In contrast to the meta-analysis in Portuguese meats, which presented a high variability among studies (see spread of measured outcomes in Fig. 1), the meta-analysis of $L$. monocytogenes in meat products did not have a significant between-study variability $(Q=22, p>0.05$; Table 6), as can be also visualised in the respective forest plot (Fig. 4). The reduced spread in the measured incidences (Fig. 4) across the great variety of meat products, may be due to the fact that $L$. monocytogenes enters the chain mainly through the raw meat; and subsequently its survival is affected by common ingredients and processing steps (i.e., salt, spices, thermal processing of some ingredients/meats, fermentation, smoking and drying), in a way that such combined effects may be comparable among meat products. Thus, the random-effects model of Eq. (1), with a between-study variability of $\tau^{2}=0$, reduced to a fixed-effects model. The twenty-six meat products were grouped in three categories: to be cooked, to be eaten raw and cured meats, in order to conduct the multilevel fixed-effects meta-analysis. The first two sub-groups contained mainly traditional meat products, many of them bearing quality labels, and the last sub-group was comprised of products elaborated with curing salts and produced to a larger scale. Although discrepancies among the mean incidence values of $L$. monocytogenes in the three categories were not large enough to cause statistical significance (i.e., the number of primary studies for the cured meats were few in comparison to the other two categories, which brought about a greater uncertainty around its mean estimate), still the mean incidence for the cured meats was numerically lower than the others (Table 6$)$. This lower rate $(4.2 \%$; 95\% CI: $1.0-16.2 \%$ ) may be due to the fact that these products contain nitrites and undergo some heat treatment; yet it can be said that this value is within the order of magnitude of the overall EU incidence of $2.4 \%$ for RTE products of meat origin except fermented sausages reported in 2010 (EFSA, 2012). It is worthwhile to mention that this EU mean incidence is taken within the context of compliance to the microbiological criterion of $L$. monocytogenes in RTE foods, expressed as a percentage of single samples and not of batch units; and in both, Portuguese studies and EFSA results, the stipulated sample weight of $25 \mathrm{~g}$ was used. The mean incidence of $L$. monocytogenes in Portuguese meat products intended to be eaten cooked (9.8\%; 95\% CI: 6.6-14.4\%) was high and not different $(\mathrm{p}>0.05)$ from the mean occurrence in fermented sausages (8.3\%; 95\% CI: 5.1-13.1\%; Table 6). Although the doses (concentration) of $L$. monocytogenes in these products may as well be low, this is an outcome that merits further investigation since such fermented meats are of high consumption and commonly eaten in Portugal without any further cooking that would reduce the risk of contracting the pathogenic agent by the consumers. Although it may not be directly comparable, at EU level the non-compliance of $L$. monocytogenes in fermented sausages sampled at processing plants was of 1.0\% in 2011

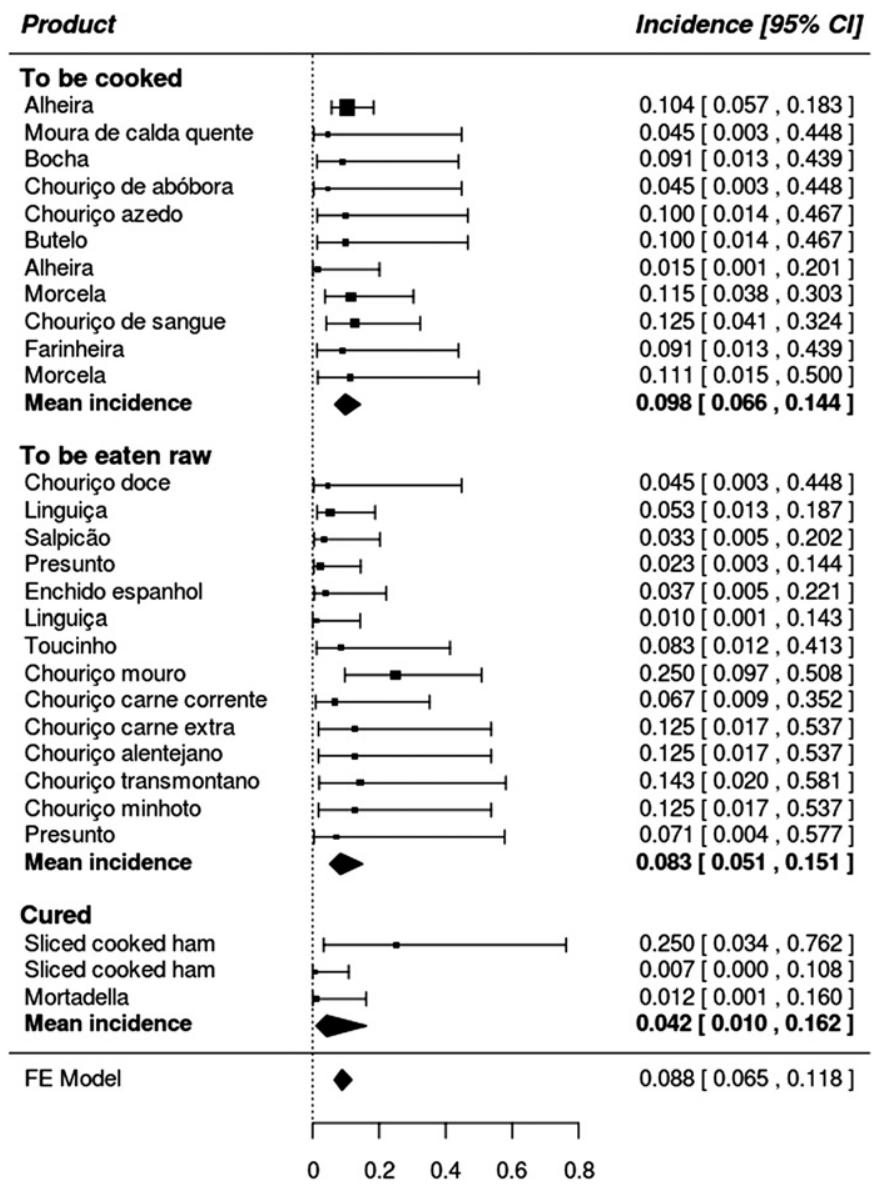

Fig. 4. Forest plot of the multilevel random-effects model of incidence of $L$. monocytogenes in Portuguese meat products. 
Incidence [95\% Cl]

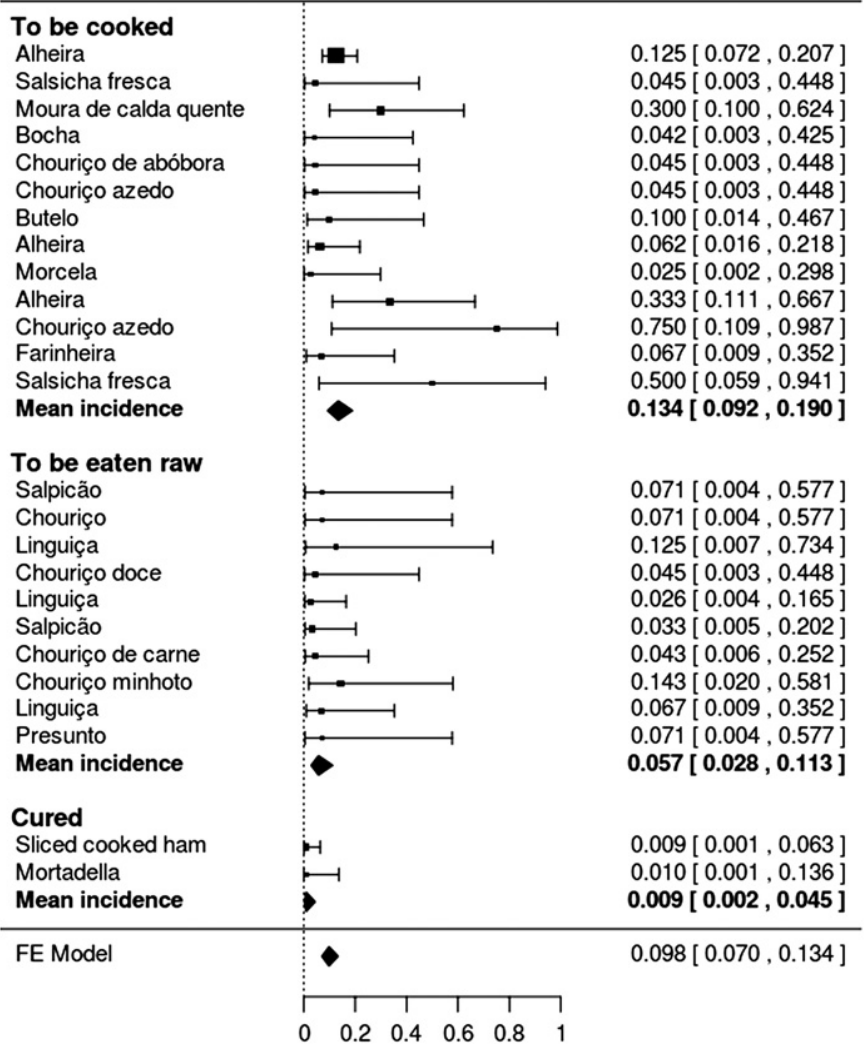

Fig. 5. Forest plot of the multilevel random-effects model of incidence of Salmonella spp. in Portuguese meat products.

(EFSA, 2013), which is a level fairly below the meta-analysed estimate for Portugal. These results underscore the necessity, firstly, to understand the risk factors in the processing of traditional meat products contributing to the pathogen's high prevalence; and secondly, to assess suitable risk-based control measures along production.

The meta-analysis of Salmonella spp. in meat products, like the metaanalysis of $L$. monocytogenes referred above, also led to a fixed-effects solution, as there was no significant variability among products

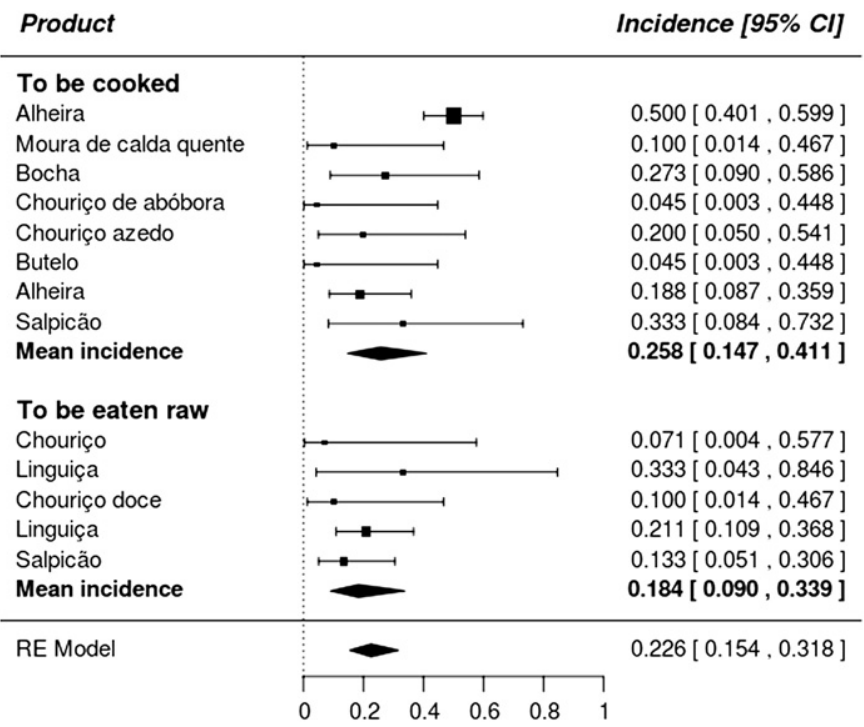

Fig. 6. Forest plot of the multilevel random-effects model of incidence of $S$. aureus in Portuguese meat products.
$\left(\mathrm{Q}=32, \mathrm{p}>0.05\right.$; and hence $\tau^{2}=0$ in Table 6 ). Again, the homogeneity in the measured incidences of Salmonella spp., despite the great variety of meat products considered, (Fig. 5) was noteworthy. The fact, that the combined effects of ingredients and processing on the viability of Salmonella along production may be comparable among the different meat products, could explain the absence of between-study heterogeneity in Salmonella occurrence. The overall mean incidence of Salmonella in Portuguese meat products was high (9.7\%; 95\% CI: 7.0-13.4\%) and did not differ $(p>0.05)$ from the mean incidence of $L$. monocytogenes (8.8\%; 95\% CI: 6.5-11.8\% in Table 6). In the case of cured meats, the incidence rate of Salmonella spp. (0.9\%; 95\% CI: $0.2-4.5 \%$ ) was considerably lower than the incidence of L. monocytogenes (4.2\%; 95\% CI: 1.0-16.2\%), which may be due to the lower resistance of Salmonella spp. to curing agents, heat treatment and cold ripening (Hwang et al., 2009). Among the three meat product categories compared by the multilevel metaanalysis (Table 6), there were significant differences in mean Salmonella occurrence, with the traditional meat products intended to be eaten cooked having the highest incidence (13.4\%; 95\% CI: 9.2-19.0\%). This level of non-compliance to the Salmonella EU microbiological criterion (in single samples unit) was higher than the EU levels reported in 2011 for the following related categories (EFSA, 2013): poultry meat preparations intended to be eaten cooked (6.8\%), meat preparations from other species than poultry intended to be eaten cooked $(1.1 \%)$, and meat products from poultry intended to be eaten cooked (1.1\%). Given such a high incidence of Salmonella in the Portuguese meat products to be cooked, and the severity of this pathogen, actions should be enabled to lower Salmonella prevalence in the pork industry as well as to instruct consumers of the importance of fully cooking the raw traditional meat products and avoiding cross contamination. On the other hand, the meat products intended to be eaten raw presented a lower Salmonella incidence of 5.7\% (95\% CI: $2.8-11.3 \%$ in Table 6), which, nonetheless, was still numerically higher than the EU average for the meat preparations intended to be eaten raw in 2011 (from 0 to 1.4\%; EFSA, 2013). It is worthy to mention that since 2008 the highest level of non-compliance with the EU Salmonella microbiological criteria generally occurred in food of meat origin with minced meat and meat preparations from poultry intended to be eaten cooked having the highest level of non-compliance.

A different scenario was noticed for the meta-analysis conducted on the presence of S. aureus in Portuguese meat products (Fig. 6). There, a significant heterogeneity among products was observed $(Q=33$, $\mathrm{p}<0.05$ ) with an $\mathrm{I}^{2}$ suggesting that $40 \%$ of the total variability in measured occurrences can be attributed to the variability product to product. Even after meat products were categorised in 'to be eaten raw' and 'to be eaten cooked', there was some remaining between-product variability (residual $\mathrm{QE}=24, \mathrm{p}<0.05$ ) in $S$. aureus incidence. Unlike L. monocytogenes and Salmonella spp., whose incidence rates were rather homogeneous among the meat products, the heterogeneity in the occurrence of $S$. aureus can only reveal the variability in hygiene among the different meat products during manufacturing. On average, $22.6 \%$ (95\% CI: 15.4-31.8\%; Table 6) of the Portuguese meat product samples are expected to be contaminated with this pathogen. The high occurrence of S. aureus in these meat products is an indicator of hygiene deficiency during processing. For instance, for Alheira (a raw meat product, first in Fig. 6), a product whose processing implies extensive manipulation, the incidence of S. aureus was the highest (50\%). In the EU, staphylococcal enterotoxins were the causative agent of $6 \%$ (435 outbreaks) of all outbreaks reported in 2011; and along with other toxins produced by Clostridium and Bacillus, they ranked second as responsible agents of all the foodborne outbreaks in the EU, only after salmonellosis. In Portugal, and for the same year, 6 confirmed outbreaks due to staphylococcal toxins occurred, involving a total of 90 human cases. It is also known that the largest proportion of strong-evidence outbreaks caused by staphylococcal toxins is attributed to mixed food including meats (40\%) (EFSA, 2013). Giletto and Fyffe (1998) indicated that the food vehicles most frequently involved in intoxication by $S$. aureus, are cooked 

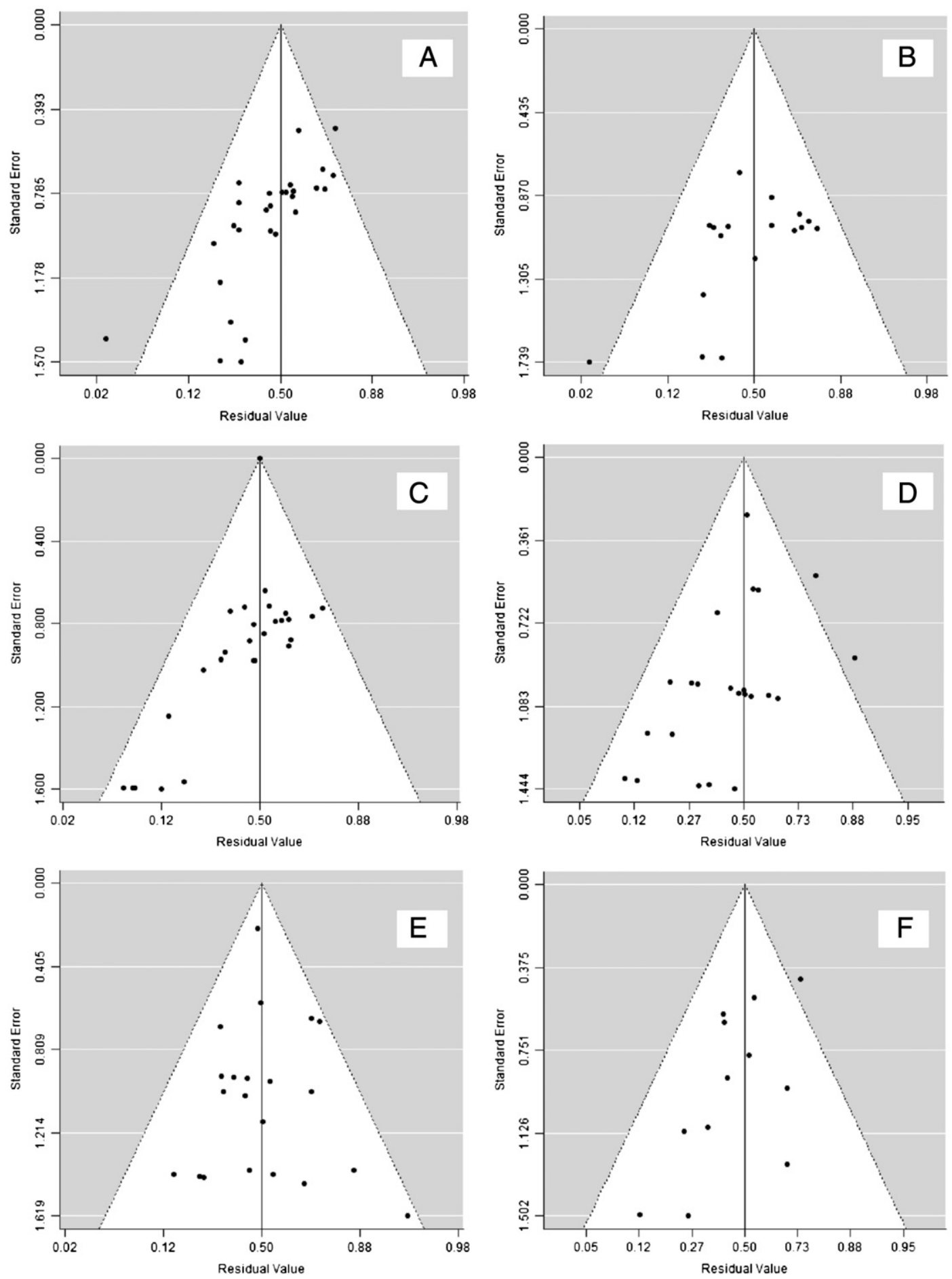

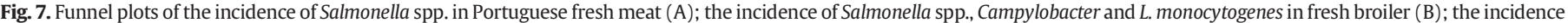
of Salmonella, VTEC, Y. enterocolitica and S. aureus in pork (C); and the incidence of L. monocytogenes (D), Salmonella spp. (E) and S. aureus (F) in Portuguese meat products.

refrigerated meats and meat products, such as turkey meat, roasted meat, ham and fermented meat products as well as bakery products containing cream. Thus, the outcome of this meta-analysis, which points towards a very high incidence of $S$. aureus in both meat products to be cooked (25.8\%; 95\% CI: 15.7-39.3\%) and meat products to be eaten raw (18.4\%; 95\% CI: 9.7-31.9\%) may support the current epidemiological situation of foodborne outbreaks in Portugal; at least to some extent as also other foods can be vehicles of staphylococcal enterotoxins. Furthermore, considering that the background microflora might limit the growth of $S$. aureus and therefore, the toxin production, further research should be carried out from a dose-response perspective.
As part of this study, publication bias was also investigated for each of the six multilevel meta-analyses conducted. Firstly, this was done by the construction of a funnel plot, which relates the mean incidence value from each primary study (or its residual after removing the covariate effects in the case of a multilevel meta-analysis) with its respective standard error as a measure of the level of confidence in the results of such primary study (for further details on the funnel plot, refer to Whitehead, 2002). There was a general tendency (Fig. 7) in having very few or a total absence of publications reporting high incidence values (higher residuals in the $x$-axis of the funnel plot) from small sample sizes (higher standard errors). This can be verified by the blank right 
bottom area in most funnel plots (Fig. 7). Nevertheless, some caution should be taken in identifying this phenomenon directly as a proof of publication bias, since it is quite common that a small sample size will fail to detect any pathogen if this is present in lower concentrations. Said otherwise, it is likely that a sample size consisting of five sample units will not have the statistical power to detect Salmonella spp. if the true prevalence of this pathogen in the food under question is very low. For this reason, in microbiological surveys of absence/presence of pathogens in foods, in order to accurately estimate the pathogen's prevalence, a large sample size is commonly required when its concentration in food is known to be low. This is the same phenomenon which produces the high number of zero counts normally observed in microbial data (Gonzales-Barron \& Butler, 2011). Thus, some caution should be taken when interpreting the funnel plots of incidence data as the blank right bottom area is not necessarily a proof of publication bias. Another approach to test publication bias is to investigate the effect of the study size directly by including the total sample size of a study as explanatory variable in a multilevel meta-analysis. Results of these multilevel metaanalyses (not shown) suggested that there was no significant effect of sample size on the observed incidences. Hence, as the presence of unpublished small-size studies reporting high prevalence is very unlikely, it is highly probable that the effect size outcomes (mean incidences) presented in these meta-analysis are not affected by publication bias.

\section{Conclusion}

The systematic review conducted in this research allowed to recognise the sparseness of knowledge on the incidence of pathogens in meats and meat products produced in Portugal. This meta-analysis study provided the first pooled incidence estimates for pathogens in specific meat categories, which are more robust and reliable than single study estimates. For the meta-analyses conducted on Portuguese meats categorised by origin, a greater number of incidence observations from primary studies were sourced for Salmonella in the different meats and Campylobacter in broiler meat than in all the other pathogen-meat combinations. The meta-analysed mean occurrence rate of Campylobacter in broiler meat (40\%) was found to be nearly ten times higher than that of Salmonella (4.4\%), although both levels were well within EU ranges. The lower incidence of Salmonella in broiler meat may be explained by the positive impact of the national control programmes in flocks of laying hens, breeding flocks and broiler flocks in place from 2008. In other fresh meat categories (i.e., bovine meat, pork, minced beef and minced pork), the Salmonella mean incidence values for Portugal were in all cases slightly to moderately higher than EU averages, being lowest in fresh bovine (1.9\%) and highest for pig meat (12.6\%). Furthermore, the semi-quantitative risk ranking in Portuguese pork assigned to Salmonella spp. and Y. enterocolitica (6.8\% occurrence) the risk categories of critical and major, respectively. Considering that, in Portugal the meat of pig origin has the highest consumption per capita, it is essential that a comprehensive pork carcass safety assurance be implemented. The current monitoring programme, consisting in testing for Salmonella in pig carcasses at the slaughterhouses, per se will not lead to any risk mitigation unless reduction targets are set to be achieved for Salmonella and Y. enterocolitica in/on chilled pig carcasses. It is equally necessary that, earlier in the food chain, risk management strategies such as differentiation of both pig batches and abattoirs as well as onfarm strategies such as categorisation of pig herds and herd health programmes be implemented in Portugal. It was surprising to find few primary studies reporting high occurrences of $L$. monocytogenes in Portuguese broiler (50\%) and S. aureus in pork (50\%), which are issues of concern that should be addressed by further research. This metaanalysis also highlighted the areas where there are gaps of knowledge such as the Salmonella serovars in bovine and broiler meats, the occurrence of VTEC in fresh bovine meat, $Y$. enterocolitica in fresh bovine and broiler meats, Campylobacter in pork, and in general the lack of information on the presence of toxin-producing pathogens in raw meats.
In the case of the Portuguese meat products, incidence data was only available for L. monocytogenes, Salmonella spp. and S. aureus. Data gaps were recognised for toxin-producing microorganisms such as Clostridium spp. and Bacillus cereus. The overall incidence of S. aureus (22.6\%) in the Portuguese meat products was significantly higher than those of L. monocytogenes (8.8\%) and Salmonella (9.7\%), which indicates a breakdown in processing hygiene. Bringing together the great variety of meat products produced in Portugal, it was found that the meat products 'intended to be eaten cooked' had mean incidences generally higher than the meat products 'to be eaten raw' for the three pathogens assessed. Nevertheless, since the mean occurrence rates or non-compliance rates to the EU microbiological criteria for both $L$. monocytogenes ( $9.8 \%$ in products to be cooked and $8.3 \%$ in products to be eaten raw) and Salmonella ( $13.4 \%$ in products to be cooked and $5.7 \%$ in products to be eaten raw) were considerably higher than EU levels for RTE products in comparable categories, it is essential that Portuguese food safety agencies take actions for the maintenance of good hygiene practices in the production and processing of traditional meat products. Putting all information together, this meta-analysis work revealed a clearer picture of the state of knowledge on the incidence of the most important foodborne pathogens in Portuguese-produced meats and meat products. It may also assist national food safety authorities and policy makers in the prioritisation of microbiological hazards in the specific meat type categories, and can equally aid researchers to provide direction for future investigation.

\section{Acknowledgments}

Dr. Gonzales-Barron wishes to acknowledge the financial support provided by the Portuguese Foundation for Science and Technology (FCT) through the award of a five-year Investigator Fellowship (IF) in the mode of Development Grants (IF/00570).

\section{References}

Almeida, G., Mena, C., \& Carneiro, L. (1998). Pesquisa de Salmonella spp. em produtos cárneos fumados e de salsicharia. Lisbon: Escola Superior de Biotecnologia, Universidade Católica Portuguesa (Available from: http://repositorio.ucp.pt/bitstream/10400.14/ 5613/1/com-nac_1999_esb_1062_Almeida_Gon\%C3\%A7alo_15.pdf)

Antunes, P., Reu, C., Sousa, J., Pestana, N., \& Peixe, L. (2002). Incidence and susceptibility to antimicrobial agents of Listeria spp. and Listeria monocytogenes isolated from poultry carcasses in Porto, Portugal. Journal of Food Protection, 65, 1888-1893.

Baptista, F. M. (2010). Salmonella in pigs and pork in Denmark and Portugal. PhD Thesis. Use of risk-based principles to achieve cost-effective surveillance strategies. Copenhagen: Faculty of Life Sciences, University of Copenhagen (Available from: http://www.iph.life.ku.dk/forskning/Forskningsprojekter/Salmonella/ /media/ Iph/Salmonella_papers/PhDThesis_Filipa\%20Baptista_March\%202011.ashx)

Borges, A.C. F. (2009). Antibiorresistência em estirpes de Campylobacter spp. isoladas em frangos num matadouro em Portugal. Master Thesis. Lisbon: Faculty of Veterinary Medicine, Universidade Técnica de Lisboa (Available from: https://www.repository. utl.pt/bitstream/10400.5/1891/3/TESE\%20DOC.pdf)

Bryk, A. S., \& Raudenbush, S. W. (1992). Hierarchical linear models: Applications and data analysis methods. Newbury Park, CA: Sage (512 pp.).

Cochran, W. G. (1954). The combination of estimates from different experiments Biometrics, 10, 101-129.

Cox, N. A., Bailey, J. S., \& Berrang, M. E. (1997). The presence of Listeria monocytogenes in the integrated poultry industry. Journal of Applied Poultry Science, 6, 116-119.

Den Besten, H. M. W., \& Zwietering, M. H. (2012). Meta-analysis for quantitative microbiological risk assessments and benchmarking data. Trends in Food Science and Technology, 25, 34-49.

DerSimonian, R., \& Laird, N. (1986). Meta-analysis in clinical trials. Controlled Clinical Trials, 7, 177-188.

Djeniyi, B., Wegener, H. C., Jensen, N. E., \& Bisgaard, M. (1996). Listeria monocytogenes in poultry and poultry products: Epidemiological investigations in seven Danish abattoirs. Journal of Applied Bacteriology, 80, 395-401.

EFSA (2005). The community summary report on trends and sources of zoonoses, zoonotic agents and antimicrobial resistance in the European Union in 2004. EFSA Journal, 310 (Available from: http://www.efsa.europa.eu/en/efsajournal/doc/310ar pdf)

EFSA (2006). The community summary report on trends and sources of zoonoses, zoonotic agents, antimicrobial resistance and foodborne outbreaks in the European Union in 2005. EFSA Journal, 94 (Available from: http://www.efsa.europa.eu/en/ efsajournal/pub/94r.htm)

EFSA (2007). The community summary report on trends and sources of zoonoses, zoonotic agents, antimicrobial resistance and foodborne outbreaks in the European Union in 2006. EFSA Journal, 130 (Available from: http://www.efsa.europa.eu/en/ efsajournal/pub/130r.htm) 
EFSA (2009). The community summary report on trends and sources of zoonoses and zoonotic agents in the European Union in 2007. EFSA Journal, 223 (Available from: http://www.efsa.europa.eu/en/efsajournal/pub/223r.htm)

EFSA (2010a). Analysis of the baseline survey on the prevalence of Campylobacter in broiler batches and of Campylobacter and Salmonella on broiler carcasses in the EU, 2008 , part A: Campylobacter and Salmonella prevalence estimates. EFSA Journal, 1503, 1-100 (Available from: http://www.efsa.europa.eu/en/efsajournal/pub/1503.htm)

EFSA (2010b). The community summary report on trends and sources of zoonoses, zoonotic agents and food-borne outbreaks in the European Union in 2008. EFSA Journal, 8(1), 1496 (Available from: http://www.efsa.europa.eu/en/efsajournal/pub/1496 htm)

EFSA (2011a). EFSA panels on biological hazards (BIOHAZ), on contaminants in the food chain (CONTAM), and on animal health and welfare (AHAW); scientific opinion on the public health hazards to be covered by inspection of meat (swine). EFSA Journal, 9(10), 2351 (Available from: http://www.efsa.europa.eu/en/efsajournal/ doc/2351.pdf)

EFSA (2011b). The European Union summary report on trends and sources of zoonoses, zoonotic agents and food-borne outbreaks in 2009. EFSA Journal, 9(3), 2090 (Available from: http://www.efsa.europa.eu/en/efsajournal/pub/2090.htm)

EFSA (2012). The European Union summary report on trends and sources of zoonoses, zoonotic agents and food-borne outbreaks in 2010. EFSA Journal, 10(3), 2597 (Available from: http://www.efsa.europa.eu/en/efsajournal/pub/2597.htm)

EFSA (2013). The European Union summary report on trends and sources of zoonoses, zoonotic agents and food-borne outbreaks in 2011. EFSA Journal, 11(4), 3129 (Available from: http://www.efsa.europa.eu/en/efsajournal/pub/3129.htm)

Esteves, A., Aymerich, T., Garriga, M., Patarata, L., Fontes, M. C., \& Martins, C. (2006a) Tracing Salmonella in Alheira processing plants. Journal of Applied Microbiology. 103, 1-10.

Esteves, A., Patarata, L., Saraiva, C., \& Martins, C. (2008). Assessment of the microbiologica characteristics of industrially produced alheira, with particular reference to foodborne pathogens. Journal of Food Safety, 28, 88-102.

Esteves, A., Saraiva, C., Fontes, M. C., \& Martins, C. (2006b). Qualidade higiénica seguranca de produtos de salsicharia Transmontana provenientes de produtores particulares. Revista Portuguesa de Ciências Veterinárias, 101, 109-114.

FAO (1998). Food quality and safety systems - a training manual on food hygiene and the hazard analysis and critical control point (HACCP) system, section 3. Food and Agriculture Organization of the United Nations. Rome, Italy: Publishing Management Group FAO Information Division (Available from: http://www.fao.org/docrep/w8088e/ w8088e00.HTM)

Ferreira, M. C., Fraqueza, M. J., \& Barreto, A. S. (2007). Avaliação do prazo de vida útil da salsicha fresca. Revista Portuguesa de Ciências Veterinárias, 102, 141-143.

Giletto, A., \& Fyffe, J. G. (1998). A novel ELISA format for the rapid and sensitive detection of Staphylococcal enterotoxin A. Bioscience Biotechnology Biochemical, 62, 2217-2222.

Gomes-Neves, E., Antunes, P., Tavares, A., Themudo, P., Cardoso, M. F., Gärtner, F., et al (2012). Salmonella cross-contamination in swine abattoirs in Portugal: Carcasses, meat and meat handlers. International Journal of Food Microbiology, 157, 82-87.

Gonzales Barron, U., Bergin, D., \& Butler, F. (2008). A meta-analysis study of the effect of chilling on Salmonella prevalence on pork carcasses. Journal of Food Protection, 71(7), 1330-1337.

Gonzales Barron, U., Soumpasis, I., Butler, F., Duggan, S., Prendergast, D., \& Duffy, G. (2009). Estimation of prevalence of Salmonella spp. on pig carcasses and pork joints using a quantitative risk assessment model aided by meta-analysis. Journal of Food Protection, 72(2), 274-285.

Gonzales-Barron, U., \& Butler, F. (2011). The use of meta-analytical tools in risk assessment for food safety. Food Microbiology, 28(4), 823-827.

Gonzales-Barron, U., Cadavez, V., Sheridan, J., \& Butler, F. (2013). Modelling the effect of chilling on the occurrence of Salmonella on pig carcasses at study, abattoir and batch levels by meta-analysis. International Journal of Food Microbiology, 163(2-3), 101-113.

Grieg, J.D., Waddell, L., Wilhelm, B., Wilkins, W., Bucher, O., Parker, S., et al. (2012). The efficacy of interventions applied during primary processing on contamination of beef carcasses with Escherichia coli. Food Control, 27(2), 385-397.

Hedges, L. V., \& Vevea, J. L. (1998). Fixed- and random-effects models in meta-analysis. Psychological Methods, 3, 486-504.

Higgins, J. P. T., \& Thompson, S. G. (2002). Quantifying heterogeneity in a meta-analysis. Statistics in Medicine, 21, 1539-1558.

Hox, J. J., \& De Leeuw, E. (2003). Multilevel models for meta-analysis. In S. P. Reise, \& N Duan (Eds.), Multilevel modelling: Methodological advances, issues and applications (pp. 90-111). New Jersey: Lawrence Erlbaum Associates.
Hunter, J. E., \& Schmidt, F. L. (1990). Methods of meta-analysis: Correcting error and bias in research findings. Newbury Park, CA: Sage.

Hwang, C. A., Porto-Fett, A.C. S., Juneja, V. K., Ingham, S.C., Ingham, B., \& Luchansky, J. B. (2009). Modelling the survival of Escherichia coli 0157:H7, Listeria monocytogenes and Salmonella Typhimurium during fermentation, drying and storage of soudjouk-style fermented sausage. International Journal of Food Microbiology, 129, 244-252.

ICMSF (2002). Microorganisms in foods 7, microbiological testing in food safety management. International Commission for the Microbiological Specifications of Foods. : Blackie Academic and Publishers (362 pp.)

Loura, C. A.C., Almeida, R. C. C., \& Almeida, P. F. (2005). The incidence and level of Listeria spp. and Listeria monocytogenes contamination in processed poultry at a poultry processing plant. Journal of Food Safety, 25, 19-29.

McQuestin, O., Shadbolt, C. T., \& Ross, T. (2009). Quantification of the relative effects of temperature, $\mathrm{pH}$ and water activity on inactivation of Escherichia coli in fermented meat by meta-analysis. Applied and Environmental Microbiology, 75, 6963-6972.

Mena, C., Almeida, G., Carneiro, L., Teixeira, P., Hogg, T., \& Gibbs, P. A. (2004). Incidence of Listeria monocytogenes in different food products commercialized in Portugal. International Journal of Food Microbiology, 21, 213-216.

Mena, C., Rodrigues, D., Silva, J., Gibbs, P., \& Teixeira, P. (2008). Occurrence, identification and characterization of Campylobacter species isolated from Portuguese poultry samples collected from retail establishments. Journal of Poultry Science, 87, 187-190.

Mendes, J. I. S. (2013). Qualidade Nutricional e Microbiológica de Enchidos. Master Thesis. Bragança, Portugal: Escola Superior Agrária, Instituto Politécnico de Bragança.

Noble, J. H. (2006). Meta-analysis: Methods, strengths, weaknesses and political uses. Journal of Laboratory and Clinical Medicine, 147, 7-20.

Raudenbush, S. W., \& Bryk, A. S. (1985). Empirical Bayes meta-analysis. Journal of Educational Statistics, 10, 75-98.

Sánchez, J., Dohoo, I. R., Christensen, J., \& Rajic, A. (2007). Factor influencing the prevalence of Salmonella spp. in swine farms: a meta-analysis approach. Preventive Veterinary Medicine, 81, 148-177.

Sargeant, J. M., Amezcua, M., Rajic, A., \& Waddell, L. (2005). A guide to conducting systematic reviews in agri-food public health. Canada: Food Safety Research and Response Network (Available from: http://www.fsrrn.net/UserFiles/File/conductingsysreviewsenglish[1]. pdf)

Simonová, J., Vázlerová, M., \& Steinhauserová, I. (2007). Detection of pathogenic Yersinia enterocolitica serotype $\mathrm{O} 3$ by biochemical, serological and PCR methods. Czech Journal of Science, 25(4), 214-220.

Smith, T. C., Harper, A. L., Nair, R., Wardyn, S. E., Hanson, B.M., Ferguson, D.D., et al. (2011). Emerging swine zoonoses. Vector Borne Zoonotic Diseases, 11(9), 1225-1234.

Soultos, N., Koidis, P., \& Madden, R. H. (2003). Presence of Listeria and Salmonella spp. in retail chicken in Northern Ireland. Letters in Applied Microbiology, 37(5), 421-423.

Sutton, A. J., Abrams, K. R., \& Jones, D. R. (2001). An illustrated guide to the methods of meta-analysis. Journal of Evaluation in Clinical Practice, 7(2), 135-148.

Van den Noortgate, W., \& Onghena, P. (2003). Multilevel meta-analysis: A comparison with traditional meta-analytical procedures. Educational and Psychological Measurement, 63(5), 765-790

Vaz-Velho, M., Almeida, G., Mena, C., Carneiro, L., \& Freitas, A. (1998). Pesquisa de Listeria monocytogenes em produtos cárneos fumados e de salsicharia. Arquivos do Instituto Nacional de Saúde, 22. (pp. 33-39) (Available from: http://repositorio.ucp.pt/ handle/10400.14/6887)

Veiga, A., Lopes, A., Carrilho, E., Silva, L., Dias, M. B., Seabra, M. J., et al. (2012). Perfil de risco dos principais alimentos consumidos em Portugal Lisbon, Portugal: Autoridade de Segurança Alimentar e Económica (ASAE) (Available from: http://www.fipa.pt/ userfiles/file/i005411.pdf)

Viechtbauer, W. (2010). Conducting meta-analyses in R with the metafor package. Journal of Statistical Software, 36, 1-48.

Vose, D. (2008). Risk analysis: A quantitative guide (3th ed.)West Sussex, England: John Wiley \& Sons, Ltd (735 pp.).

Whitehead, A. (2002). Meta-analysis of controlled clinical trials. West Sussex, England: John Wiley \& Sons, Ltd.

WHO (2003). WHO surveillance programme for control of foodborne infections and intoxications in Europe 8th report 1999-2000 country reports: Portugal : World Health Organisation (Available from: http://www.bfr.bund.de/internet/8threport/8threp_fr.htm)

Whyte, P., McGill, K., Monahan, C., \& Collins, J.D. (2004). The effect of sampling time on the levels of microorganisms recovered from broiler carcasses in a commercial slaughter plant. Journal of Food Microbiology, 21, 59-65. 